\title{
Melatonin Promotes the Chilling Tolerance of Cucumber Seedlings by Regulating Antioxidant System and Relieving Photoinhibition
}

\author{
Xiaowei Zhang, Yiqing Feng, Tongtong Jing, Xutao Liu, Xizhen Ai and Huangai Bi* \\ State Key Laboratory of Crop Biology, Key Laboratory of Crop Biology and Genetic Improvement of Horticultural Crops \\ in Huanghuai Region, College of Horticulture Science and Engineering, Shandong Agricultural University, Tai'an, China
}

OPEN ACCESS

Edited by:

Michael Moustakas, Aristotle University of Thessaloniki,

Greece

Reviewed by:

Nafees A. Khan,

Aligarh Muslim University, India

Zisheng Luo,

Zhejiang University, China

*Correspondence:

Huangai $B$

bhg163@163.com

Specialty section:

This article was submitted to

Plant Abiotic Stress,

a section of the journal

Frontiers in Plant Science

Received: 05 October 2021 Accepted: 10 November 2021 Published: 09 December 2021

Citation:

Zhang $X$, Feng $Y$, Jing T, Liu $X$, Ai $X$ and Bi $H$ (2021) Melatonin

Promotes the Chilling Tolerance

of Cucumber Seedlings by Regulating Antioxidant System and Relieving

Photoinhibition.

Front. Plant Sci. 12:789617. doi: 10.3389/fpls.2021.789617
Chilling adversely affects the photosynthesis of thermophilic plants, which further leads to a decline in growth and yield. The role of melatonin (MT) in the stress response of plants has been investigated, while the mechanisms by which MT regulates the chilling tolerance of chilling-sensitive cucumber remain unclear. This study demonstrated that MT positively regulated the chilling tolerance of cucumber seedlings and that $1.0 \mu \mathrm{mol} \cdot \mathrm{L}^{-1}$ was the optimum concentration, of which the chilling injury index, electrolyte leakage (EL), and malondialdehyde (MDA) were the lowest, while growth was the highest among all treatments. MT triggered the activity and expression of antioxidant enzymes, which in turn decreased hydrogen peroxide $\left(\mathrm{H}_{2} \mathrm{O}_{2}\right)$ and superoxide anion $\left(\mathrm{O}_{2} \cdot{ }^{-}\right)$accumulation caused by chilling stress. Meanwhile, MT attenuated the chillinginduced decrease, in the net photosynthetic rate (Pn) and promoted photoprotection for both photosystem II (PSII) and photosystem I (PSI), regarding the higher maximum quantum efficiency of PSII (Fv/Fm), actual photochemical efficiency $\left(\Phi P S_{\|}\right)$, the content of active P700 $\left(\Delta \mathrm{l} / \mathrm{I}_{0}\right)$, and photosynthetic electron transport. The proteome analysis and western blot data revealed that MT upregulated the protein levels of PSI reaction center subunits (PsaD, PsaE, PsaF, PsaH, and PsaN), PSIl-associated protein PsbA (D1), and ribulose-1,5-bisphosphate carboxylase or oxygenase large subunit (RBCL) and Rubisco activase (RCA). These results suggest that MT enhances the chilling tolerance of cucumber through the activation of antioxidant enzymes and the induction of key PSI-, PSII-related and carbon assimilation genes, which finally alleviates damage to the photosynthetic apparatus and decreases oxidative damage to cucumber seedlings under chilling stress.

Keywords: melatonin, reactive oxygen species, antioxidant system, photosynthesis, chilling stress, cucumber

\section{INTRODUCTION}

For warm climate crops, chilling is considered as a considerable challenge among all abiotic stresses. The previous study showed that low-temperature stress mainly affects light energy utilization and photosynthetic efficiency by disrupting electron transport chains in chloroplasts and mitochondria, leading to reactive oxygen species (ROS) accumulation (Fan et al., 2015). ROS of cells have a strong affinity for membranes, DNA, proteins, carbohydrates, and lipids in plant cells (Anjum et al., 2015; Jajic et al., 2015) 
and eventually induce cell membrane damage in plants, which severely affects growth and development (Fan et al., 2015; Kazemi-Shahandashti and Maali-Amiri, 2018; Ma et al., 2018). Therefore, it is particularly important to remove excessive ROS in cells. Plants have developed protective mechanisms to regulate the balance between frequent production and scavenging of ROS (Rai et al., 2012). Plants can improve antioxidant enzyme activities to resist the harmful effects of excessive accumulated ROS (Hasanuzzaman et al., 2012). Previous studies have shown that excess ROS induced by chilling stress causes an oxidative damage to plants, which first activates the antioxidant system to respond to oxidative stress. For instance, chilling stress upregulates the gene expression and activities of superoxide dismutase (SOD), catalase (CAT), peroxidase (POD), ascorbate peroxidase (APX), and glutathione reductase (GR) and also the antioxidants such as ascorbate and glutathione (Pan et al., 2020; Zhang et al., 2020). Thus, improving antioxidant capacity is considered as an important method for increasing the chilling tolerance of plants.

Photosynthesis is particularly sensitive to metabolism and developmental processes which can be affected by cold stress (Barrero-Gil et al., 2016). For instance, chilling stress causes the obvious decrease in photosystem II (PSII) and photosystem I (PSI) activity, which inhibits the electron transfer chain and further leads to the generation of singlet oxygen $\left({ }^{1} \mathrm{O}_{2}\right)$ and superoxide in the thylakoid membrane (Terashima et al., 1998; Asada, 2006; Tikkanen et al., 2015; Zhuang et al., 2019). Additionally, the decrease in photosynthetic enzyme activity and messenger RNA (mRNA) abundance, such as ribulose-1,5-bisphosphate carboxylase or oxygenase (Rubisco), transketolase (TK), fructose-1,6-bisphosphate aldolase (FBA), and sedoheptulose-1,7- bisphosphatase (SBPase), are the main reasons for the reduction in photosynthesis under chilling stress (Bi et al., 2015, 2017; Ding et al., 2016; Cai et al., 2018). Thus, how to improve the photosynthetic capacity of chilling sensitive plants under low temperature is an important area of research.

Plants sense chilling signals through hormones to further induce physiological and biochemical reactions (Eremina et al., 2016). Among the different plant hormones, melatonin $(N$ acetyl-5-methoxytryptamine, MT) is a new type of hormone-like substance. It is a small molecule indole that was first discovered in the bovine pineal gland in Lerner et al. (1958). The effects of MT on animals were then studied such as circadian rhythm, mood, sleep and body temperature, physical activity, food intake, retinal physiology, sexual activity, seasonal reproduction, and the immune system (Maronde and Stehle, 2007; Pandi-Perumal et al., 2008; Jan et al., 2009; Hardeland et al., 2012; Carrillo-Vico et al., 2013). The existence of MT in higher plants was demonstrated in 1995 (Dubbels et al., 1995; Hattori et al., 1995). Subsequently, the vital role of MT in plants was gradually reported, such as simulating growth by promoting lateral root formation, plant height, and leaf surface area (Chen et al., 2018; Erdal, 2019) and also improving seed germination (Marta et al., 2016). Moreover, MT was reported as a signaling molecule that participates in the response of plants to abiotic and biotic stresses, which can also stimulate an increase in endogenous MT concentration (Zuo et al., 2014; Shi et al., 2015; Li et al., 2016; Arora and Bhatla, 2017).
In 2004, MT was first reported to relieve the chilling stress damage of carrot suspension cells (Lei et al., 2004). Subsequently, MT was found to stimulate the germination of cucumber seeds by protecting the membrane structure against peroxidation under chilling stress (Posmyk et al., 2009). Within cucumber, $200 \mu \mathrm{mol} \cdot \mathrm{L}^{-1} \mathrm{MT}$ significantly promoted the activities of SOD, APX, GR, monodehydroascorbate reductase (MDHAR), and dehydroascorbate reductase (DHAR), which are involved in the ascorbate-glutathione cycle and accelerated the scavenging of ROS under chilling stress (Zhao et al., 2016). More importantly, MT promoted the chilling tolerance of chlorophyll b-deficient mutant wheat offspring via protecting photosynthetic electron transport (Li X. N. et al., 2017).

Cucumber (Cucumis sativus L.) is an important vegetable crop that is cultivated worldwide. However, chilling stress severely affects cucumber productivity and quality (Lee et al., 2002; Yu et al., 2002). Previous studies have shown that fruits and even whole seedlings of cucumber produce physiological damage when exposed to chilling stress, especially when they are cultivated in greenhouses during the winter (Cabrera and Saltveit, 1990). Although it has been demonstrated that MT is involved in the antioxidant system and photosynthesis in response to chilling, the optimal concentration and mechanism of regulating the chilling tolerance of cucumber seedlings have not been studied thoroughly. In this study, nutrient solution culture was adopted to explore the effects of different concentrations of MT on cucumber growth and physiological metabolism after chilling stress. We found that MT treatment could improve cold resistance and the effect of $1.0 \mu \mathrm{mol} \cdot \mathrm{L}^{-1} \mathrm{MT}$ was optimal. For the mechanism of regulating chilling tolerance, proteomics analysis and western blot were used to further study PSI and PSII reaction center activities. The study sheds light on the molecular and physiological mechanism by which MT responds to chilling stress.

\section{MATERIALS AND METHODS}

Cucumber (Jinyou 35) seeds (bought from Tianjin Kerun Cucumber Research Institute, Tianjin, China) were germinated on petri dishes $(8.6 \mathrm{~cm}$ in diameter) with moisture filter paper in the dark at $28^{\circ} \mathrm{C}$ for 1 day, and then germinated seeds were sowed to the nutritional box $(8.0 \mathrm{~cm}$ in diameter and $8.0 \mathrm{~cm}$ in height $)$ filled with base material in a solar greenhouse. The seedlings were routinely managed. The conditions were as follows: maximum of $800-1000 \mu \mathrm{mol} \mathrm{m} \mathrm{m}^{-2} \cdot \mathrm{s}^{-1}$ photon flux density (PFD) and $25-31^{\circ} \mathrm{C}$ or $13-21^{\circ} \mathrm{C}$ day or night temperature under a 13 -h photoperiod. At the one-leaf-stage, the seedlings were transferred to black plastic containers $(36.5 \mathrm{~cm}$ in length, $27.5 \mathrm{~cm}$ in width, and $11 \mathrm{~cm}$ in height) with $1 / 2$ Hoagland nutrient solution and then $0 \mu \mathrm{mol} \cdot \mathrm{L}^{-1}, 0.3 \mu \mathrm{mol} \cdot \mathrm{L}^{-1}, 0.6 \mu \mathrm{mol} \cdot \mathrm{L}^{-1}, 1.0 \mu \mathrm{mol} \cdot \mathrm{L}^{-1}$, $1.5 \mu \mathrm{mol} \cdot \mathrm{L}^{-1}$, and $2.0 \mu \mathrm{mol} \cdot \mathrm{L}^{-1} \mathrm{MT}$ were added until cucumber seedlings were at the two-leaf stage. Twenty-four hours later, all seedlings were exposed to low temperatures $\left(8^{\circ} \mathrm{C} / 5^{\circ} \mathrm{C}\right.$ day or night) and the seedlings treated with $0 \mu \mathrm{mol} \cdot \mathrm{L}^{-1} \mathrm{MT}\left(\mathrm{H}_{2} \mathrm{O}\right)$ were used as the control. Then, leaf samples were taken at $0,1,3$, and 5 days from 4 to 5 plants $(n=3)$ for the following analyses. 


\section{Measurement of Leaf Area}

Leaf area was determined as described previously (Gong and Xiang, 2001).

\section{Measurement of Malondialdehyde, Electrolyte Leakage, and Chilling Injury Index}

Malondialdehyde (MDA) content was measured using the thiobarbituric acid (TBA) colorimetric method (Heath and Packer, 1968). Electrolyte leakage (EL) was estimated as described by Dong et al. (2013). For chilling injury index examination, the seedlings were graded according to the standard described by Semeniuk et al. (1986), and the chilling injury index was calculated using the following equation: chilling injury index $=\Sigma$ (plants of different grade $\times$ grade $) /[$ total plants $\times 5$ (the maximum grade)].

\section{Determination of Reactive Oxygen Species}

Cellular hydrogen peroxide $\left(\mathrm{H}_{2} \mathrm{O}_{2}\right)$ was clearly visible with an inverted fluorescence microscope using the $\mathrm{H}_{2} \mathrm{O}_{2}$ fluorescent probe 2', 7'-dichlorodihy drofluorescein diacetate $\left(\mathrm{H}_{2} \mathrm{DCFDA}\right)$ (MCE, Cat. No. HY-D0940, Shanghai, China) according to Galluzzi and Kroemer (2014). The leaf disks $(0.6 \mathrm{~cm}$ in diameter) of the seedlings subjected to the various treatments were soaked in $20 \mathrm{mM}$ HEPES-NaOH buffer (containing $20 \mu \mathrm{MH}_{2} \mathrm{O}_{2}$ fluorescent probe, $\mathrm{pH}$ 7.5) for 30 min under dark conditions at $25^{\circ} \mathrm{C}$. After rinsing with the HEPES-NaOH buffer three times (15 min each time), the $\mathrm{H}_{2} \mathrm{O}_{2}$ production was visual in the form of green coloration (excitation at $488 \mathrm{~nm}$ and emission at $522 \mathrm{~nm}$ ) under an inverted fluorescence microscope (Leica DMi8; Leica, Germany). Cellular superoxide anion $\left(\mathrm{O}_{2}{ }^{-}\right)$was detected using dihydroethidium (DHE) (Fluorescence Biotechnology Co. Ltd, Cat. No. 15200, Beijing, China) as described by Galluzzi and Kroemer (2014). The leaf disks $(0.6 \mathrm{~cm}$ in diameter) were soaked in $10 \mathrm{mM}$ Tris-HCl buffer (containing $10 \mu \mathrm{M}$ DHE, $\mathrm{pH}$ 7.5) and placed at $37^{\circ} \mathrm{C}$ in darkness for $30 \mathrm{~min}$. After dying, the samples were washed two times ( $15 \mathrm{~min}$ each time) using Tris$\mathrm{HCl}$ buffer. The orange-red fluorescence of $\mathrm{O}_{2}{ }^{--}$(excitation at $490 \mathrm{~nm}$ and emission at $520 \mathrm{~nm}$ ) was clearly visible with the inverted fluorescence microscope.

The quantitation of $\mathrm{H}_{2} \mathrm{O}_{2}$ content was performed according to the instructions specified in the plant $\mathrm{H}_{2} \mathrm{O}_{2}$ Assay Kit (Nanjing Jiancheng Bioengineering Institute, Nanjing, China). The $\mathrm{O}_{2}{ }^{-}$production rate was determined using the method presented by Wang and Luo (1990).

\section{Activity of Antioxidant Enzymes Assay}

Cucumber leaves $(0.5 \mathrm{~g})$ were ground using $3 \mathrm{ml}$ phosphate buffer $(50 \mathrm{mM}, \mathrm{pH} 7.8)$ and centrifuged the resulting extract at $12,000 \mathrm{~g}$ at $4^{\circ} \mathrm{C}$ for $20 \mathrm{~min}$. The supernatant was reserved at $4^{\circ} \mathrm{C}$ and prepared to measure the activities of antioxidant enzymes (Cho and Park, 2000). SOD activity was determined according to Beyer and Fridovich's (1987) method. POD activity was measured with the method of Omran (1980). CAT activity was assayed according to Maehly and Chance (1955). APX activity was detected according to Nakano and Asada (1987), and GR activity was assayed used the method of Foyer and Halliwell (1976).

\section{Gas-Exchange Parameters Assay}

The gas-exchange parameters were assayed with a photosynthetic instrument (Ciras-3, PP-systems International, Hitchin, Hertfordshire, United Kingdom) and controlled PFD $\left(600 \mu \mathrm{mol} \cdot \mathrm{m}^{-2} \cdot \mathrm{s}^{-1}\right), \mathrm{CO}_{2}$ concentration $\left(360-380 \mathrm{mg} \cdot \mathrm{L}^{-1}\right)$, and leaf temperature $\left(25^{\circ} \mathrm{C} \pm 1^{\circ} \mathrm{C}\right)$ from the beginning to end.

\section{Measurements of Chlorophyll Fluorescence Imaging}

Chlorophyll fluorescence imaging of the cucumber seedlings placed in the dark for $45 \mathrm{~min}$ was visualized using a chlorophyll fluorescence imaging system (Imaging PAM, Walz, Wurzburg, Germany) with a computer-operated PAM control system (Tian et al., 2017).

\section{Chlorophyll a Fluorescence Transient and $820 \mathrm{~nm}$ Transmission Assay}

The Chlorophyll a Fluorescence Transient (OJIP) curve and $820 \mathrm{~nm}$ transmission were assayed according to the method of Liu et al. (2020). Leaves were acclimated in the dark for approximately $40 \mathrm{~min}$ and measured with an integral multifunctional plant efficiency analyzer (M-PEA, Hansatech, King's Lynn, Norfolk, United Kingdom). Based on the method of Strasser et al. (2010), the O-J segment of the OJIP curve was standardized. $\mathrm{O}$ is the minimum fluorescence, $\mathrm{K}$ is $300 \mu \mathrm{s}$, and $\mathrm{J}$ is $2 \mathrm{~ms}$. Calculation of fluorescence parameters: $\mathrm{O}-\mathrm{J}$ section standardization: $\mathrm{V}_{O-J}=\left(\mathrm{F}_{t}-\mathrm{F}_{0}\right) /\left(\mathrm{F}_{J}-\mathrm{F}_{0}\right) ; \Delta \mathrm{V}_{O-J}=\mathrm{V}_{O-J^{-}}$ $\mathrm{V}_{O-J}$ (control); number of reaction centers per unit area $R C / C S_{m}=\left(\mathrm{ABS} / \mathrm{CS}_{m}\right) /(\mathrm{ABS} / \mathrm{RC})$; efficiency of electron moving beyond QA $\left(\psi_{0}\right)=\mathrm{ET} / \mathrm{TR}=1-\mathrm{V}_{J}$; the capacity of electron transport from PSII to PSI $\varphi \mathrm{E}_{0}=\mathrm{ET}_{0} / \mathrm{ABS}=\left(1-\mathrm{F}_{0} / \mathrm{F}_{m}\right) \times \psi_{0}$ (Bi et al., 2016). To measure the relative content of the active PSI reaction center, $\Delta \mathrm{I} / \mathrm{I}_{0}$ was measured according to Zhang et al. (2011) and computational formula is as follows (Salvatori et al., 2014): $\Delta \mathrm{I} / \mathrm{I}_{0}=\left(\mathrm{I}_{0}-\mathrm{I}_{m}\right) / \mathrm{I}_{0}\left(\mathrm{I}_{0}\right.$, the initial reflection signal between 0.4 and $10 \mathrm{~ms} ; \mathrm{I}_{m}$, minimum reflection signal under $820 \mathrm{~nm}$ far-red illumination).

\section{Sodium Dodecyl Sulfate-Polyacrylamide Gel Electrophoresis and Immunoblot Analysis}

To extract total protein, 0.2 g leaf samples were ground with liquid nitrogen and extraction buffer $(20 \mathrm{mM}$ tricine, $1 \mathrm{mM}$ sodium ascorbate, $400 \mathrm{mM}$ sorbic alcohol, $10 \mathrm{mM}$ $\mathrm{NaHCO}_{3}, 5 \mathrm{mM}$ EDTA. $\mathrm{Na}_{2}$, and $5 \mathrm{mM} \mathrm{MgCl}$ ) was added. After centrifugation at 2,000 $\mathrm{g}$ for $15 \mathrm{~min}, 5 \times$ loading buffer (CW0027S, Beijing ComWin Biotech Co., Ltd., Beijing, China) was added and then boiled at $100^{\circ} \mathrm{C}$ for $15 \mathrm{~min}$. $10 \%$ sodium dodecyl sulfate-polyacrylamide gel electrophoresis (SDS-PAGE) gel was prepared to separate proteins. Antibodies specific to the PsbA (D1), PSI reaction center subunit II (PsaD), ribulose-1,5-bisphosphate carboxylase or oxygenase (Rubisco) large subunit (RbcL), and Rubisco activase (RCA) proteins 
(ATCG00020, AT1G03130, ATCG00490, AT2G39730, PhytoAB company, San Francisco, CA, United States) were used to detect D1, PsaD, RbcL, and RCA and followed by incubation with horseradish peroxidase-conjugated anti-rabbit IgG antibody (ComWin Biotech Co., Ltd., Beijing, China). The eECL Western Blot Kit (CW00495, ComWin Biotech Co., Ltd., Beijing, China) was used to detect immune responses, and the ChemiDoc ${ }^{\mathrm{TM}}$ XRS imaging system (Bio-Rad Laboratories, Inc., Hercules, CA, United States) was used to record the chemiluminescence.

\section{Tandem Mass Tag Quantitative Proteomics Analysis}

Samples were obtained after $9 \mathrm{~h}$ of chilling stress and then fully ground with liquid nitrogen and extracted with lysis buffer (containing $10 \mathrm{mM}$ dithiothreitol and $1 \%$ protease inhibitor). An equal volume of Tris-balanced phenol was added and centrifuged at 5,500 $\mathrm{g}$ at $4^{\circ} \mathrm{C}$ for $10 \mathrm{~min}$. The supernatant was retained and 5-fold volume of $0.1 \mathrm{M}$ ammonium acetate or methanol was added to precipitate overnight. The precipitates were washed with methanol and acetone, respectively, and redissolved with $8 \mathrm{M}$ urea.

Dithiothreitol was added to the protein solution to make a final concentration of $5 \mathrm{mM}$ and then reduced at $56^{\circ} \mathrm{C}$ for $30 \mathrm{~min}$. Then, iodoacetamide was added to a final concentration of $11 \mathrm{mM}$ and incubated at room temperature for $15 \mathrm{~min}$ in darkness. The urea concentration of the sample was diluted to less than $2 \mathrm{M}$. Trypsin was added in a 1:50 mass ratio (trypsin: protein), and enzymatic hydrolysis was performed overnight at $37^{\circ} \mathrm{C}$. Trypsin was added at a mass ratio of 1:100 (trypsin: protein) again, and enzymatic hydrolysis was continued for $4 \mathrm{~h}$. After trypsin digestion, the peptides were desalted with a Strata X C18 SPE column (Phenomenex) and then vacuum freeze-dried. The peptides were dissolved in $0.5 \mathrm{M}$ triethylammonium bicarbonate (TEAB) and labeled according to the instructions of the Tandem Mass Tag (TMT) kit. The peptides were separated with high $\mathrm{pH}$ reverse-phase high-performance liquid chromatography (HPLC) using a Thermo Betasil C18 column (5 $\mu \mathrm{m}$ particles, $10 \mathrm{~mm}$ ID, $250 \mathrm{~mm}$ length), dissolved with mobile phases A ( $0.1 \%$ formic acid), and separated by an EASY-nLC 1000 UPLC system. Mobile phase A was aqueous solution containing $0.1 \%$ formic acid, and mobile phase B was acetonitrile solution containing $0.1 \%$ formic acid. Liquid phase gradient setting was as follows: $0-43 \mathrm{~min}, 6-22 \%$ phase B; $43-$ $56 \mathrm{~min}, 22-30 \%$ phase $\mathrm{B} ; 56-58 \mathrm{~min}, 30-80 \%$ phase $\mathrm{B} ; 58-60 \mathrm{~min}$, $80 \%$ phase $\mathrm{B}$, and the flow rate maintained at $300 \mathrm{~nL} / \mathrm{min}$. The peptides were separated by a UPLC system and then injected into a capillary ion source for ionization and analyzed by times TOF Pro mass spectrometry. The ion source voltage was set at $1.4 \mathrm{kV}$, and the peptide parent ions and their secondary fragments were detected and analyzed using TOF. The scanning range of secondary mass spectrometry was set to $100-1700 \mathrm{~m} / \mathrm{z}$. The data acquisition mode was parallel accumulation serial fragmentation (PASEF) mode. Secondary mass spectrometry data were retrieved using the Maxquant search engine (v1.6.5.0), and peptide length was analyzed with mass spectrometry. Finally, bioinformatics analysis was performed. The quantitative proteins were identified and analyzed with threshold value of differential expression change of 1.2 -fold and a statistically tested $t$-test $p$-value $<0.05$.

\section{RNA Extraction and Gene Expression Analysis}

Cucumber leaves were ground thoroughly with liquid nitrogen, and total RNA was extracted with TransZol reagent (Transgen, Beijing, China). First, $0.2 \mathrm{~g}$ ground powder was added $1 \mathrm{ml}$ TransZol and then mixed. After standing for $5 \mathrm{~min}, 0.2 \mathrm{ml}$ chloroform was added followed by shaking vigorously for $15 \mathrm{~s}$ and then standing for $3 \mathrm{~min}$ at room temperature. The solution was centrifuged at $10,000 \mathrm{~g}$ and $4^{\circ} \mathrm{C}$ for $15 \mathrm{~min}$, and the supernatant was retained. Then, $0.5 \mathrm{ml}$ isopropyl alcohol was added to the supernatant, mixed gently, and incubated for $10 \mathrm{~min}$ at room temperature. The sample was centrifuged at $10,000 \mathrm{~g}$ and $4^{\circ} \mathrm{C}$ for $10 \mathrm{~min}$ to remove the supernatant, and then $1 \mathrm{ml}$ of $75 \%$ ethanol was added to the precipitate. Oscillation and centrifugation were performed at $7,500 \mathrm{~g}$ and $4^{\circ} \mathrm{C}$ for $5 \mathrm{~min}$. The supernatant was removed, and the precipitation was dried at room temperature. The precipitate was dissolved in $100 \mu \mathrm{L}$ RNA solution. The resulting total RNA was reverse transcribed according to the instructions of HiScript ${ }^{\circledR}$ IIIRT SuperMix for qPCR (+gDNA wiper) (Vazyme, Nanjing, China). Genomic DNA was removed using $4 \times$ gDNA wiper Mix at $42^{\circ} \mathrm{C}$ for $2 \mathrm{~min}$. Then, $5 \times$ HiScript III qRT SuperMix containing all the components required for reverse transcription was mixed with RNA and could be used immediately for PCR at $37^{\circ} \mathrm{C}$ for $15 \mathrm{~min}$ and then $85^{\circ} \mathrm{C}$ for 5 s. Relative gene expressions were analyzed by real-time quantitative PCR (RTqPCR) using ChamQ ${ }^{\mathrm{TM}}$ Universal SYBR ${ }^{\circledast}$ qPCR MasterMix (Vazyme, Nanjing, China) according to the instructions. The predenaturation was performed at $95^{\circ} \mathrm{C}$ for $30 \mathrm{~s}$. Then, 40 cycles were performed at $95^{\circ} \mathrm{C}$ for $10 \mathrm{~s}$ and $60^{\circ} \mathrm{C}$ for $30 \mathrm{~s}$. Finally, $95^{\circ} \mathrm{C}$ for $15 \mathrm{~s}$ and $60^{\circ} \mathrm{C}$ for $60 \mathrm{~s}$ and $95^{\circ} \mathrm{C}$ for $15 \mathrm{~s}$ acquired fusion curves. The cucumber $\beta$-actin gene (Gene ID: Solyc11g005330) was used as an internal reference gene. The primers were designed and synthesized by BGItech and were shown in Table 1. qRT-PCR was performed with three biological replicates and three technical replicates.

\section{Statistical Analysis}

The experimental design was a completely randomized block design. The data are presented as the mean \pm standard deviation (SD) of three to five replicates. Analysis of variance was conducted using DPS software. Duncan's multiple range test (DMRT) was applied to statistical analysis among treatments, and the standard for significant difference was $p<0.05$.

\section{RESULTS}

\section{Exogenous Melatonin Positively Regulates the Chilling Tolerance of Cucumber Seedlings}

To study the concentration effect of MT on regulating chilling tolerance of cucumber seedlings, we treated seedlings with 0.3 , 
TABLE 1 | Primers used in quantitative real-time PCR (qRT-PCR).

\begin{tabular}{|c|c|c|}
\hline Genes & $\begin{array}{l}\text { Accession } \\
\text { numbers }\end{array}$ & Primer pairs $\left(5^{\prime}-3^{\prime}\right)$ \\
\hline \multirow[t]{2}{*}{ ACTIN } & DQ115883 & CCACGAAACTACTTACAACTCCATC \\
\hline & & GGGCTGTGATTCCTTGCTC \\
\hline \multirow[t]{2}{*}{$S O D$} & NM_001280768 & GGAAAGATGTGAAGGCTGTGG \\
\hline & & GCACCATGTTGTITCCAGCAG \\
\hline \multirow[t]{2}{*}{$P O D$} & XM_004151830 & GGTTTCTATGCCAAAAGCTGCCC \\
\hline & & CAGCTTGGTTGTTGAGGTGGAG \\
\hline \multirow[t]{2}{*}{ CAT } & NM_001308916 & AATGGCCGGAGGATGTGA \\
\hline & & CCAACGACATAGAGAAAGCCAAC \\
\hline \multirow[t]{2}{*}{$A P X$} & NM_001280706 & GTGCTACCCTGTTGTGAGTG \\
\hline & & AACAGCGATGTCAAGGCCAT \\
\hline \multirow[t]{2}{*}{$G R$} & NM_001308836 & TGATGAGGCTITGAGTTAGAGGAG \\
\hline & & AACTTTGGCACCCATACCATTC \\
\hline PsaD & Csa_3G147780 & $\begin{array}{l}\text { TATGTCATAACATGGGAATCC } \\
\text { ACCTCAATAGGGCTAACATTCT }\end{array}$ \\
\hline PsaE & Csa_2G079660 & $\begin{array}{l}\text { ATAGAGAAAAAAGATCATTCA } \\
\text { ACCACAACTGGGTATCGAGTGTT }\end{array}$ \\
\hline PsaF & Csa_1G714680 & $\begin{array}{l}\text { ATCAAAGCCACGATCGAAAAGAC } \\
\text { TCACCATTGACAAGCTCTCTG }\end{array}$ \\
\hline PsaH & Csa_3G483830 & $\begin{array}{l}\text { AGGCTGGTGCTGTGGTTGCTAAG } \\
\text { CCACGTGGCCCAAGTTCGGTGG }\end{array}$ \\
\hline PsaN & Csa_6G483300 & $\begin{array}{l}\text { ACTCCTCTGCTAATGCTGGAGT } \\
\text { TCCTTCCCTTCACACTCCAATT }\end{array}$ \\
\hline
\end{tabular}

$0.6,1.0,1.5$, and $2.0 \mu \mathrm{mol} \cdot \mathrm{L}^{-1} \mathrm{MT}$, respectively. As shown in Figure 1A, cucumber seedlings treated with $\mathrm{H}_{2} \mathrm{O}$ showed leaf-wilting and spots at advanced stages of the chilling stress. Furthermore, we examined the change in growth and lipid peroxidation of cucumber seedlings under low-temperature intensity. An increase in the chilling injury index, EL, and MDA content in cucumber seedlings treated with $\mathrm{H}_{2} \mathrm{O}$ was observed along with an increase in stress duration (Figures 1B-E). MT obviously alleviated the chilling injury of cucumber seedlings, as evidenced by the slightly wilted leaf, lower chilling index, EL, MDA content, and higher leaf area. Moreover, the alleviation effect firstly increased and then decreased with increasing concentrations of $\mathrm{MT}$ and $1.0 \mu \mathrm{mol} \cdot \mathrm{L}^{-1} \mathrm{MT}$ showed the best effect. These results illustrated that MT could improve the chilling tolerance of cucumber seedlings in a concentration-dependent manner, and $1.0 \mu \mathrm{mol} \cdot \mathrm{L}^{-1} \mathrm{MT}$ was used in further experiments.

\section{Melatonin Stimulates Antioxidative Pathways and Reduces Oxidative Stress}

Chilling stress can break the balance of reactive oxygen metabolism, which further results an oxidative damage to plants. Thus, we assessed the effect of exogenous MT on the ROS contents and antioxidant system following chilling stress at 8 or $5^{\circ} \mathrm{C}$ for 5 days. Importantly, MT accumulated less $\mathrm{H}_{2} \mathrm{O}_{2}$ and $\mathrm{O}_{2}{ }^{-}$, and inverted fluorescence microscope observations of $\mathrm{H}_{2} \mathrm{O}_{2}$ and $\mathrm{O}_{2}{ }^{-}$were consistent with the quantitative determination. For instance, the $\mathrm{H}_{2} \mathrm{O}_{2}$ content of $\mathrm{H}_{2} \mathrm{O}$-treated seedlings increased by $65.5 \%$ but MT-treated seedlings increased by $37.8 \%$, which was obviously lower as compared to $\mathrm{H}_{2} \mathrm{O}$ treatment especially at 3 days of chilling stress (Figure 2).
Moreover, we examined the impacts of MT on the activities and gene mRNA abundance of antioxidant enzymes during chilling stress. As shown in Figures 3A-E, increases in SOD, POD, CAT, APX, and GR activities in both $\mathrm{H}_{2} \mathrm{O}$ - and MTtreated cucumber seedlings were observed with the increasing of chilling stress. Notably, seedlings of MT treatment showed higher activities of the five antioxidant enzymes than the $\mathrm{H}_{2} \mathrm{O}$ treatment during chilling stress. Additionally, the regulation of antioxidant enzyme genes by MT was detected during chilling stress. The mRNA expression levels of $S O D, P O D, C A T, A P X$, and GR were significantly upregulated when the seedlings were exposed to 8 or $5^{\circ} \mathrm{C}$ for 5 days, which was positively correlated with the increased antioxidant enzyme activities of the chilling-treated seedlings (Figures 3F-J). Consistently, MT-treated seedlings displayed higher mRNA abundance of $S O D, P O D, C A T, A P X$, and GR than $\mathrm{H}_{2} \mathrm{O}$-treated seedlings, indicating that MT could enhance the antioxidant capacity to protect the membrane against oxidative damage caused by chilling stress.

\section{Melatonin-Induced Chilling Tolerance Is Associated With Improved Photosynthesis in Cucumber Seedlings}

The generation of oxidative stress is closely related to photosynthetic capacity, so we studied the effect of MT on photosynthesis. To determine whether MT could improve the photosynthetic capacity, we examined the changes in gasexchange parameters in cucumber seedlings treated with $\mathrm{H}_{2} \mathrm{O}$ and MT, respectively. As shown in Figure 4, net photosynthetic rate (Pn) and stomatal conductance (Gs) of cucumber seedlings were significantly reduced, whereas the intercellular $\mathrm{CO}_{2}$ concentration $(\mathrm{Ci})$ increased under chilling stress. Additionally, we found that MT significantly relieved the decrease in Pn and Gs induced by chilling stress.

Considering the decrease of Gs accompanied by the increase of $\mathrm{Ci}$, which suggested that the decline of Pn was mainly caused by non-stomatal factors under chilling intensity, we also determined the activities of PSII and PSI in both $\mathrm{H}_{2} \mathrm{O}$ - and MT-treated seedlings. Under normal conditions, no significant differences were observed in higher maximum quantum efficiency of PSII ( Fv/Fm) and actual photochemical efficiency between $\mathrm{H}_{2} \mathrm{O}$ and MT treatments. However, when exposed to chilling at $8^{\circ} \mathrm{C}$ or $5^{\circ} \mathrm{C}$ for 1 and 3 days, $\mathrm{H}_{2} \mathrm{O}$ and MT treatments showed dramatic decreases in $\mathrm{F}_{v} / \mathrm{F}_{m}$ and ФPSII in cucumber seedlings, but the decrease in MT was notably lower than that of $\mathrm{H}_{2} \mathrm{O}$ treatment (Figure 5A). The results showed that chilling stress caused obvious photoinhibition to cucumber seedlings, and exogenous MT could significantly reduce the damage of photoinhibition to cucumber seedlings. Meanwhile, we found that the levels of $R c / C s_{m}, \Psi_{0}$ and $\varphi \mathrm{E}_{0}$ decreased in cucumber seedlings following 5 days of chilling stress and that the changes in MT-treated seedlings were much lower (Figures 5C-E). For instance, $\varphi \mathrm{E}_{0}$ was suppressed by $62.58 \%$ in $\mathrm{H}_{2} \mathrm{O}$-treated seedlings but only by $26.86 \%$ in MT-treated seedlings after 1 days of chilling stress compared to seedlings under normal conditions. The OJIP curve at $300 \mu \mathrm{s}$ is called the K-point, and the increase in the K-point shows that the oxygen evolution complex (OEC) 

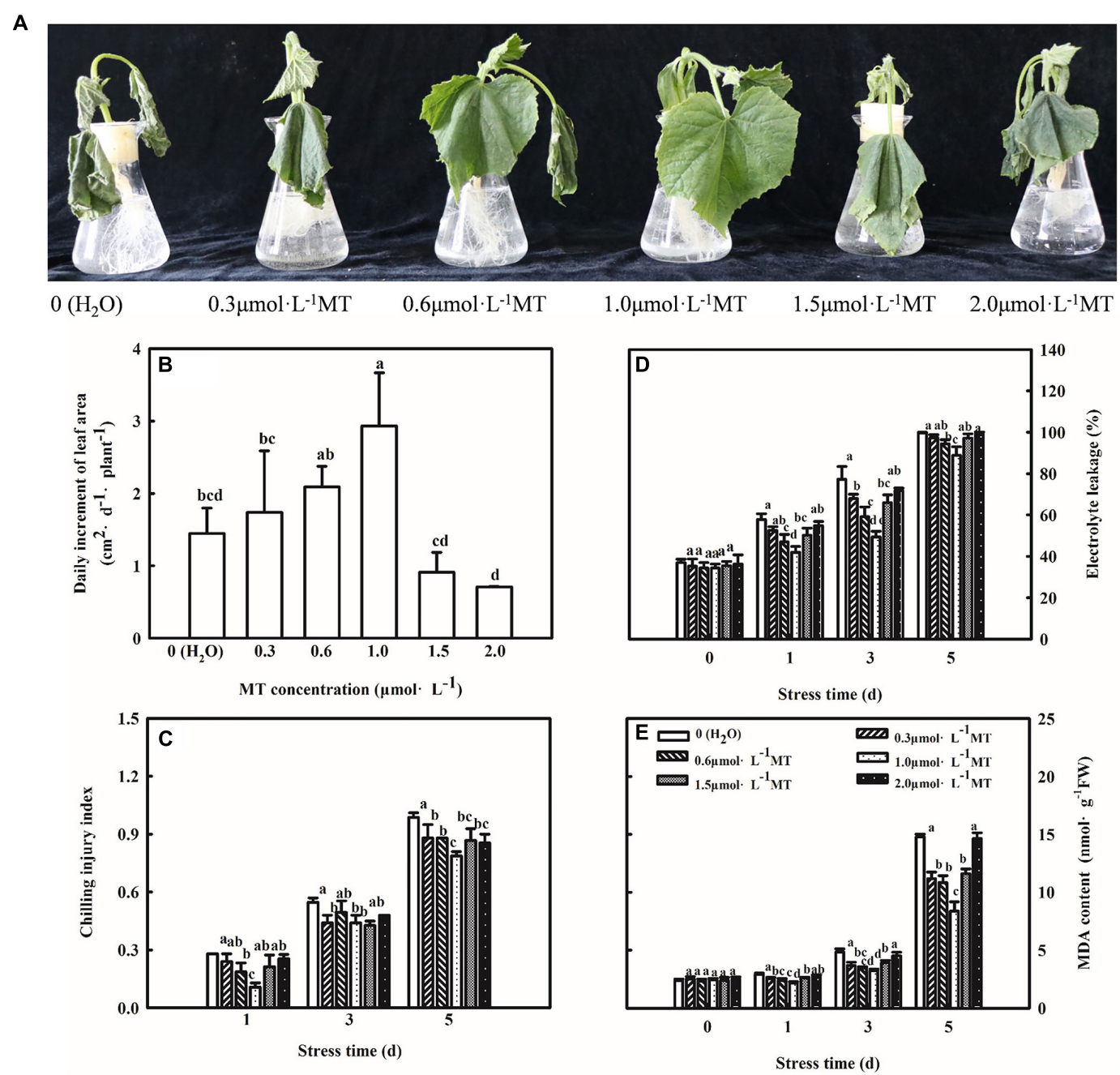

FIGURE 1 | Effect of MT on the chilling tolerance of cucumber seedlings. (A) Phenotype of seedlings. (B) Daily increment of leaf area. (C) Chilling injury index. (D) Electrolyte leakage. (E) MDA content. The two-leaf stage cucumber seedlings were treated with $0,0.3,0.6,1.0,1.5,0$ or $2.0 \mu \mathrm{mol} . \mathrm{L}^{-1} \mathrm{MT}$, respectively, for $24 \mathrm{~h}$, and then seedlings were exposed to 8 or $5^{\circ} \mathrm{C}$ for 5 days. All values shown are mean $\pm \mathrm{SD}(n=3)$. a, b, c, and d indicate that mean values are significantly different among samples $(p<0.05)$.

is damaged under stress. The K-point is a specific marker of photoinhibition of the PSII donor side. To observe the K-point, the O-J segments of the OJIP curves before and after chilling stress were standardized (Figures 5F,G). The results showed that before chilling stress, the curves of the O-J segment of the $\mathrm{H}_{2} \mathrm{O}$ and MT treatments were similar. Following of 1 day of chilling stress, the K-point of cucumber seedlings increased significantly, but the K-point of the MT treatment was significantly lower than that of the $\mathrm{H}_{2} \mathrm{O}$ treatment. Thus, the results showed that exogenous MT alleviated the damage to PSII and increased the efficiency of electron transfer under chilling stress.

Furthermore, PSI was sensitive to abiotic stresses. As shown in Figure 5B, chilling stress led to a decrease in $\triangle \mathrm{I} / \mathrm{I}_{0}$. Compared to the $\mathrm{H}_{2} \mathrm{O}$ treatment, MT showed markedly higher $\triangle \mathrm{I} / \mathrm{I}_{0}$ than the $\mathrm{H}_{2} \mathrm{O}$ treatment when seedlings were exposed to $8^{\circ} \mathrm{C}$ or $5^{\circ} \mathrm{C}$ for 5 days, demonstrating that MT could upregulate the activity of the PSI reaction center under chilling stress.

\section{Analysis of Quantitative Proteomic in Cucumber Seedlings in Response to Melatonin Under Chilling Stress}

To further confirm the possible mechanism associated with the mitigation of photosynthesis under chilling stress by MT, we detected the protein expression in cucumber seedlings sprayed with $\mathrm{H}_{2} \mathrm{O}$ and MT after $9 \mathrm{~h}$ of low-temperature treatment. Based on the criteria for significantly different expressions of $p<0.05$ and a fold change of $>1.2$ or $<1.2$ for proteins in three biological replicates, we identified 320 significantly expressed proteins in MT-treated seedlings as compared to $\mathrm{H}_{2} \mathrm{O}$-treated seedlings, including 148 upregulated proteins and 172 downregulated proteins compared with $\mathrm{H}_{2} \mathrm{O}$-treated seedlings under chilling stress (Figure 6A). Furthermore, we mainly focused on the analysis of the 148 upregulated proteins and found that the enrichment degree of upregulated proteins mainly focused on 


\section{A}
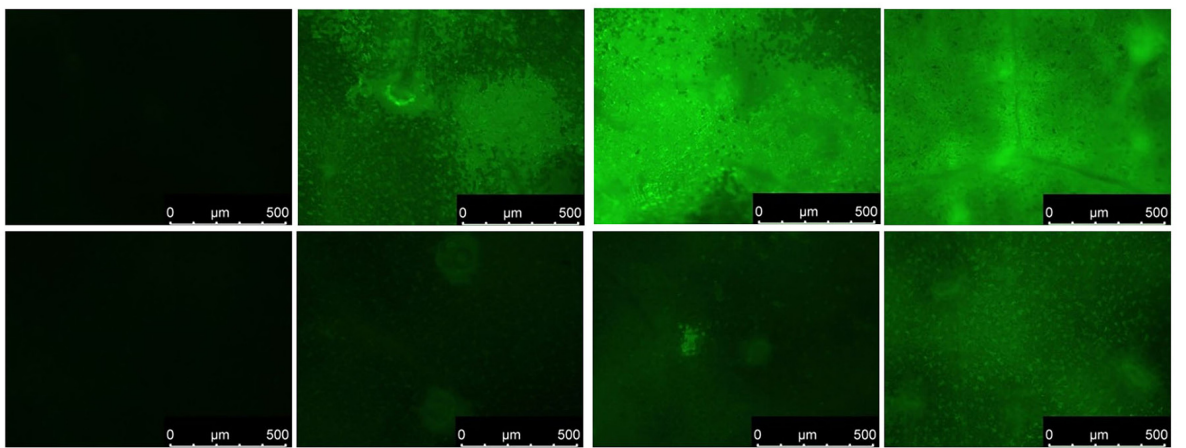

B
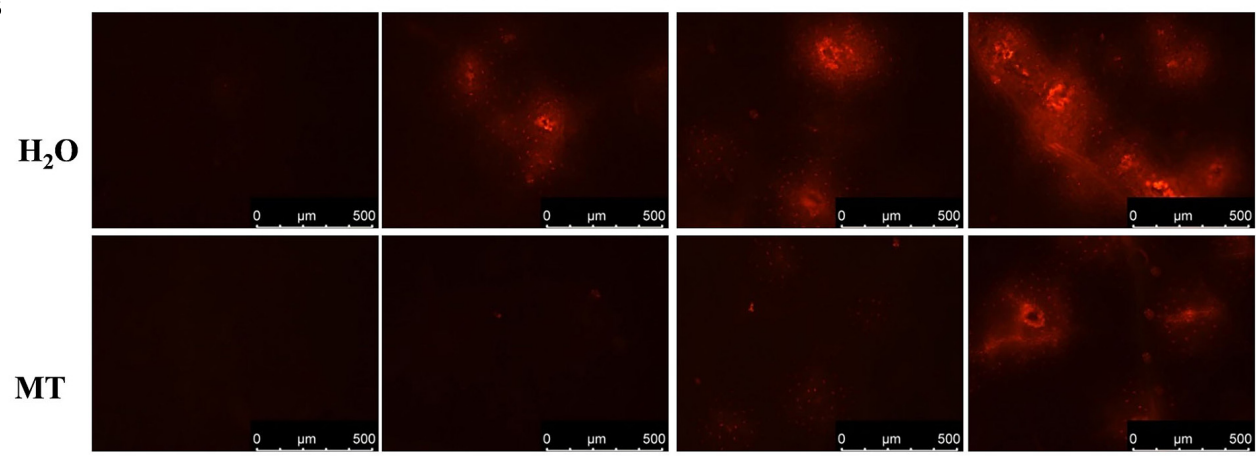

Od

$1 \mathbf{d}$

3d

5d

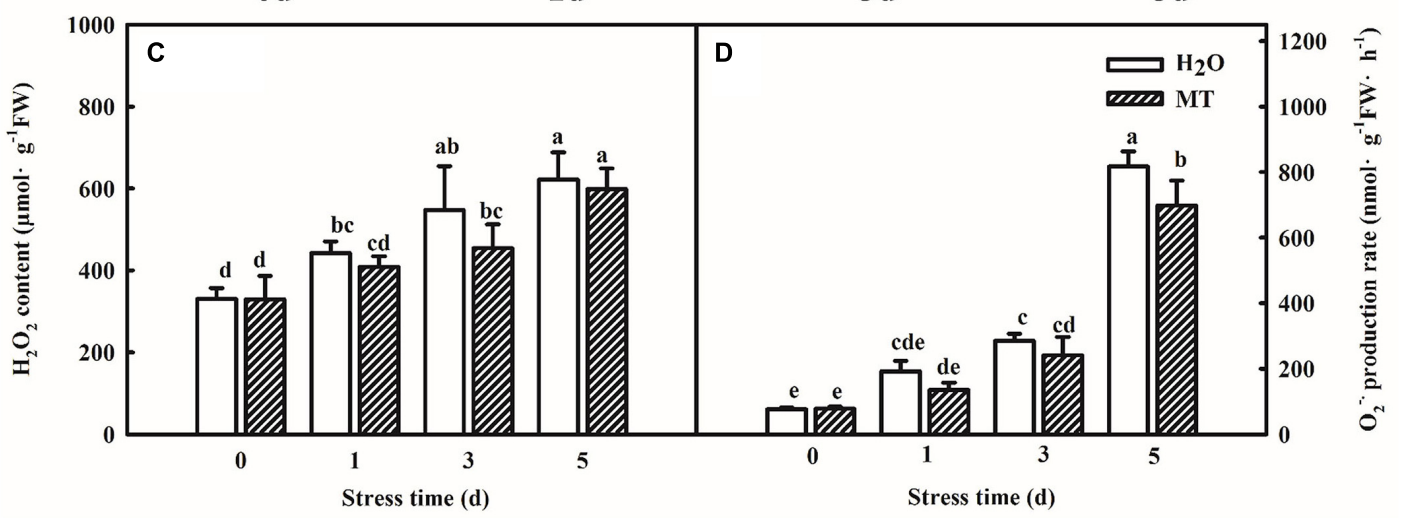

FIGURE 2 | Effect of MT on the accumulation of ROS under chilling stress. (A) $\mathrm{H}_{2} \mathrm{O}_{2}$ inverted fluorescence microscope imaging. (B) $\mathrm{O}_{2}{ }^{\cdot-}$ inverted fluorescence microscope imaging. (C) $\mathrm{H}_{2} \mathrm{O}_{2}$ content. (D) $\mathrm{O}_{2} \cdot-$ production rate. The two-leaf stage cucumber seedlings were treated with $\mathrm{H}_{2} \mathrm{O}$ and $1.0 \mu \mathrm{mol} \cdot \mathrm{L}^{-1} \mathrm{MT}$, respectively, for $24 \mathrm{~h}$, and then seedlings were exposed to 8 or $5^{\circ} \mathrm{C}$ for $0-5$ days. All values shown are mean $\pm \mathrm{SD}(n=3)$. a, b, c, d, and e indicate that mean values are significantly different among samples $(p<0.05)$.

photosynthesis pathways (Figures 6B,C), which were mainly related to PSI and light energy capture.

\section{Transcript Levels Analysis of Photosystem I-Associated Genes Induced by Melatonin Under Chilling}

\section{Stress}

Table 2 showed a partial list of the differentially expressed proteins related to PSI, such as PsaD, PsaE, PsaF, PsaH, and PsaN. To further validate our quantitative proteomic results, we measured the RNA abundance of PsaD, PsaE, PsaF, PsaH, and $P s a N$ in cucumber seedlings with quantitative RT-PCR assays after $9 \mathrm{~h}$ chilling stress, and Figure 7 displayed significantly higher mRNA abundance of PsaD, PsaE, PsaF, PsaH, and PsaN in MT-treated seedlings, compared to $\mathrm{H}_{2} \mathrm{O}$-treated seedlings. The results were highly consistent with the proteomic data, suggesting the confidence of the quantitative proteomic data.

\section{Western Blot Analysis of Photosynthesis-Associated Proteins Induced by Melatonin Under Chilling Stress}

Key enzymes in the reaction stage and PSII-related enzymes are important factors which that affect photosynthesis. Thus, we 


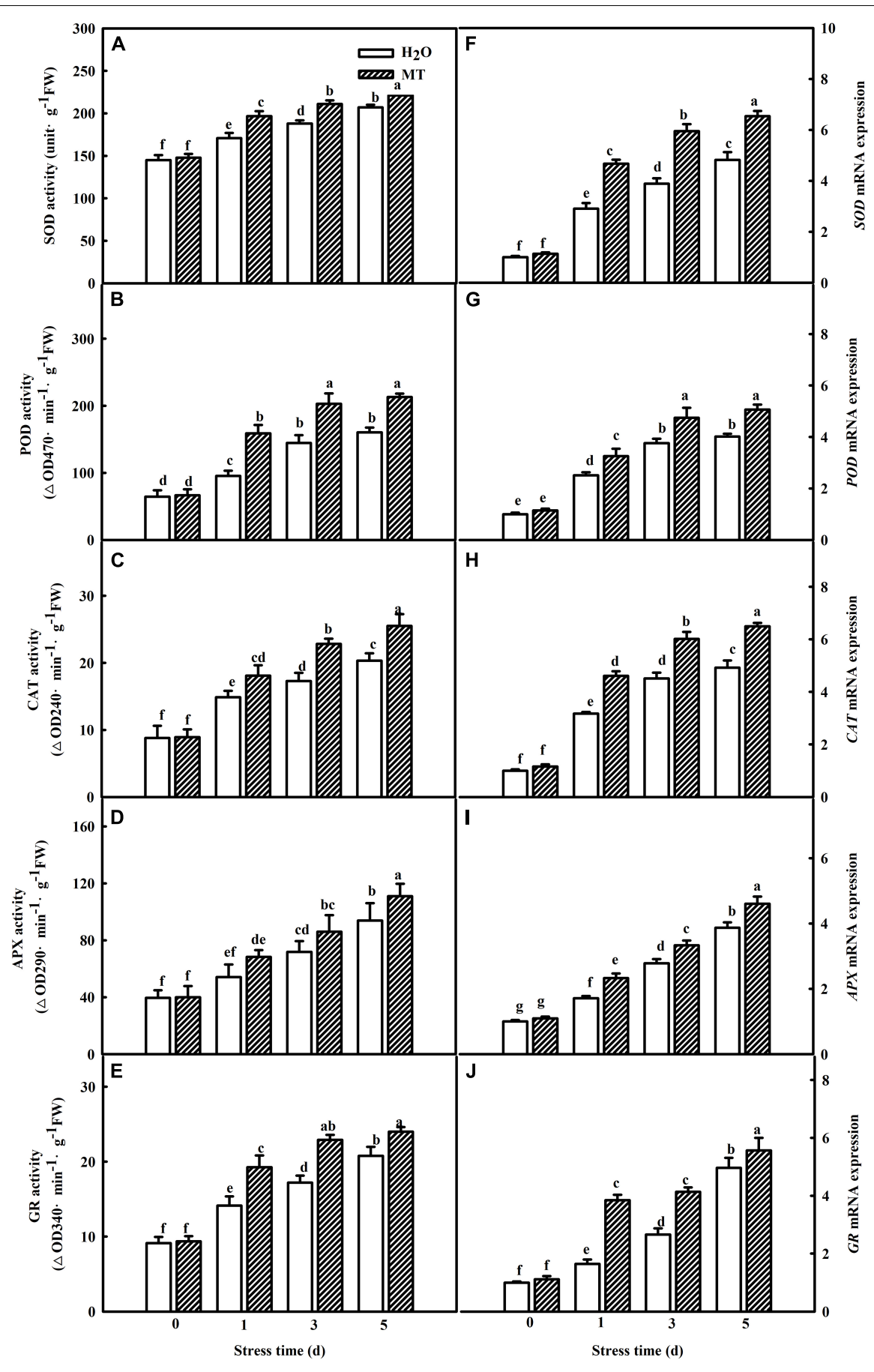

FIGURE 3 | Effect of MT on the activities and relative mRNA expressions of antioxidant enzymes in cucumber seedlings under chilling stress. (A-E) Activities of SOD, POD, CAT, APX, and GR, the second leaf was sampled for the activities assay. (F-J) Relative mRNA expressions of SOD, POD, CAT, APX, and GR, total RNA was separately isolated from the same tissues for the determination of activities and subjected to RT-PCR. The two-leaf stage seedlings were treated with $\mathrm{H}_{2} \mathrm{O}$ and $1.0 \mu \mathrm{mol} \cdot \mathrm{L}^{-1} \mathrm{MT}$, respectively, for $24 \mathrm{~h}$. Then, the seedlings were exposed to 8 or $5^{\circ} \mathrm{C}$ for 5 days. All values shown are mean $\pm \mathrm{SD}(n=3)$. a, b, $\mathrm{c}, \mathrm{d}, \mathrm{e}, \mathrm{f}$, and $\mathrm{g}$ indicate that mean values are significantly different among samples $(p<0.05)$.

chose certain key proteins involved in the photosynthetic system for western blot, and the data showed that the protein levels of RBCL, RCA, and $\mathrm{D} 1$ in $\mathrm{H}_{2} \mathrm{O}$-treated seedlings decreased significantly with increasing chilling stress time (Figure 8); however, MT obviously relieved the degradation of RBCL, RCA, and D1 induced by chilling stress. The protein level of PsaD was consistent with the proteomic data (Figure 8). The results further suggested 


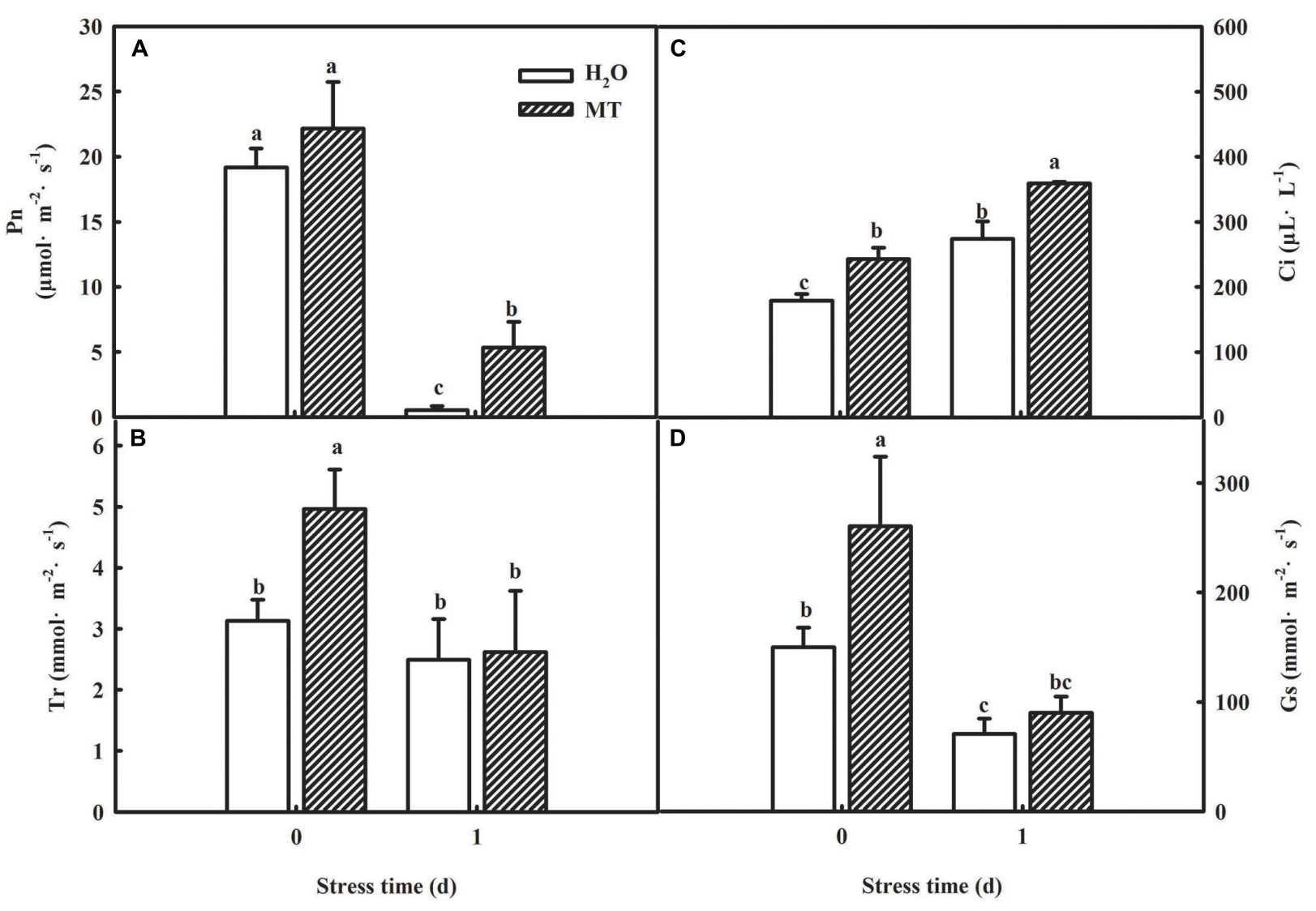

FIGURE 4 | Effect of MT on the gas-exchange parameters of cucumber seedlings under chilling stress. (A) Pn; (B) Tr; (C) Ci; (D) Gs. The two-leaf stage cucumber seedlings were treated with $\mathrm{H}_{2} \mathrm{O}$ and $1.0 \mu \mathrm{mol} \cdot \mathrm{L}^{-1} \mathrm{MT}$, respectively, for $24 \mathrm{~h}$, and then seedlings were exposed to 8 or $5^{\circ} \mathrm{C}$ for 1 days. All values shown are mean $\pm \operatorname{SD}(n=3)$. a, b, and c indicate that mean values are significantly different among samples $(p<0.05)$.

the regulatory mechanism of MT on photosynthesis under chilling stress.

\section{DISCUSSION}

Previous studies have revealed that MT was involved in tolerance to multiple abiotic stresses, including tolerance to chilling, drought, salt, and cadmium stress (Bajwa et al., 2014; Zuo et al., 2014; Li et al., 2016; Marta et al., 2016; Arora and Bhatla, 2017; Aghdam et al., 2020). In this study, the cucumber seedlings pretreated with different concentrations of MT showed changes of varying degrees in chilling injury index, EL, and MDA under chilling stress, especially with $1.0 \mu \mathrm{mol} \cdot \mathrm{L}^{-1} \mathrm{MT}$ treatment (Figure 1). These findings confirmed that MT could enhance the chilling tolerance of cucumber seedlings in a concentrationdependent manner. More importantly, MT easily showed light decomposition, and here, we added MT to the liquid nutrient solutions but not foliar application, which was better avoiding the light degradation of MT and decreasing the effective application amount of MT. For instance, MT can promote the chilling tolerance of cucumber seedlings at $100 \mu \mathrm{mol} \cdot \mathrm{L}^{-1}$ when MT is applied as a spray (Feng et al., 2021).
Ninety-five percent of the dry matter in plants comes from the photosynthesis, which is the basis for the yield. Different lines of evidence highlight the effect of MT on photosynthesis of plants (Li H. et al., 2017; Liang et al., 2019; Yan et al., 2021). MT could trigger many genes and enzymes associated with carbon and nitrogen metabolism which in turn improved photosynthesis to promote plant growth and development under abiotic stress (Debnath et al., 2019; Iqbal et al., 2021; Ren et al., 2021). Here, we found that cucumber seedlings in the MT treatment showed a higher daily increase in leaf area than those in the $\mathrm{H}_{2} \mathrm{O}$ treatment under chilling stress, which was related to the higher Pn of the MT treatment following 1 day of chilling stress (Figure 4A). However, evidence showing the regulatory mechanisms of MT on photosynthesis in plant tolerance to low-temperature intensity, particularly in chilling-sensitive crop species, is limited. Previous studies showed that the decline in Pn during chilling stress was mainly due to the decrease of activity in photosynthetic enzyme and also PSII and PSI (Bi et al., 2015; Zhang et al., 2016). Under chilling stress, PSII activity, as one of the most notable hallmarks, obviously decreases, which has been proved to contain at least 20 different subunits, and D1 protein of PSII is the most attack site under various abiotic stresses (Kong et al., 2014; Gao et al., 2018; Zhuang et al., 2019). Similarly, we 

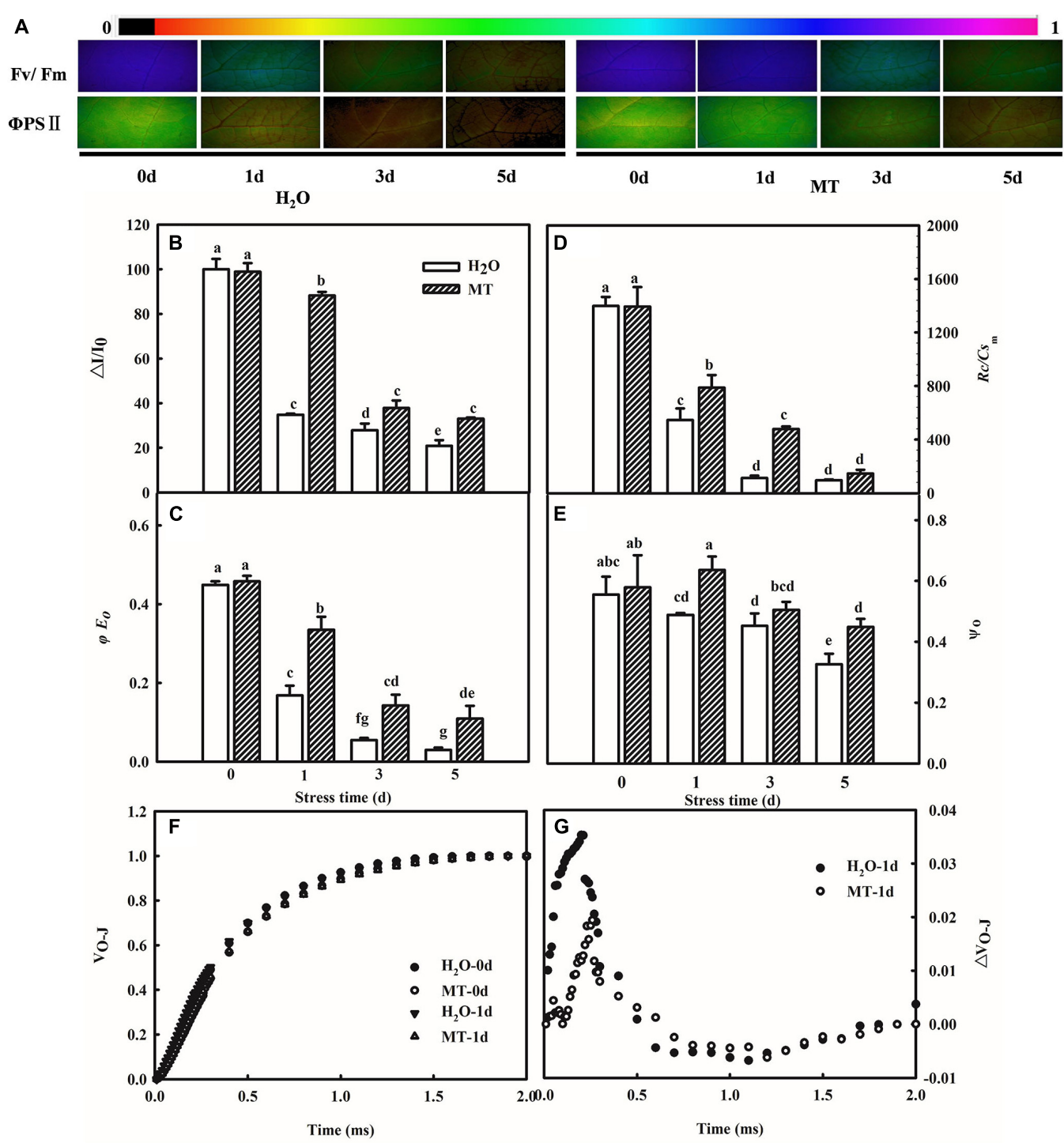

FIGURE 5 | Effect of MT on the activity of PSI and PSIl under chilling stress. (A) Fv/Fm and $\Phi P S I l ;$ (B) $\Delta \mathrm{l} / \mathrm{l}_{0}$; (C) $\varphi \mathrm{E}_{0} ;$ (D) $R c / C s m ;$ (E) $\Psi_{0} ;$ (F) $\vee_{O-J}$; (G) $\Delta V_{O-J}$. The two-leaf stage cucumber seedlings were treated with $\mathrm{H}_{2} \mathrm{O}$ and $1.0 \mu \mathrm{mol} \cdot \mathrm{L}^{-1} \mathrm{MT}$, respectively, for $24 \mathrm{~h}$, and then seedlings were exposed to $8^{\circ} \mathrm{C}$ or $5^{\circ} \mathrm{C}$ for 5 days. All values shown are mean $\pm \mathrm{SD}(n=3)$. a, b, c, d, e, f, and g indicate that mean values are significantly different among samples $(p<0.05)$.
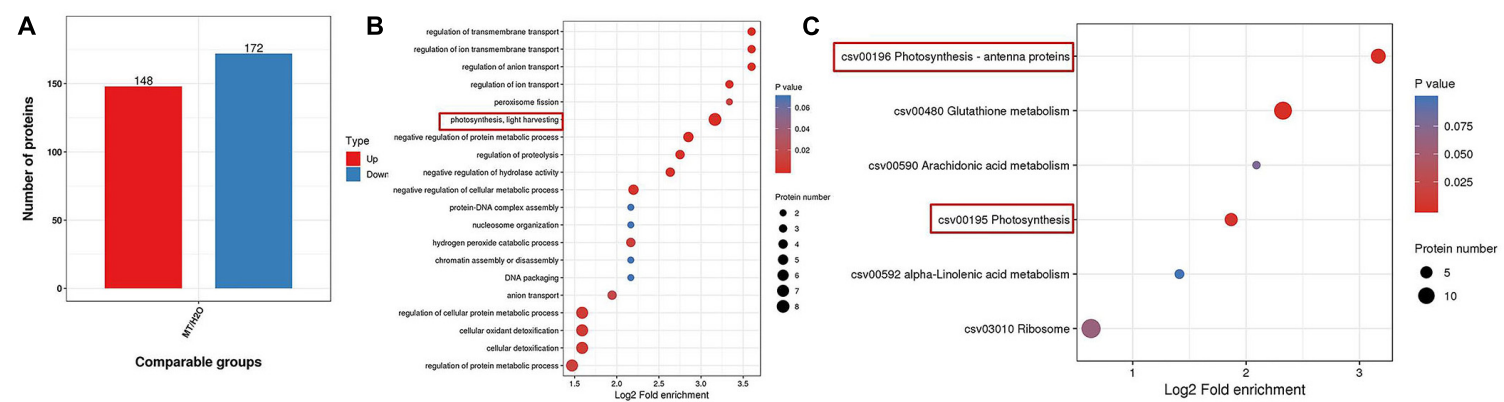

FIGURE 6 | Protein expression comparison (A), Go, and KEGG analysis of differential expressed proteins (B,C) in MT vs. $\mathrm{H}_{2} \mathrm{O}(p<0.05$ and a fold change of $>1.2$ or <1.2). The two-leaf stage cucumber seedlings were treated with $\mathrm{H}_{2} \mathrm{O}$ and $1.0 \mu \mathrm{mol} \cdot \mathrm{L}^{-1} \mathrm{MT}$, respectively, for $24 \mathrm{~h}$, and then seedlings were exposed to $5^{\circ} \mathrm{C}$ for $9 \mathrm{~h}$. The bubble size represents the number of proteins, and the bubble color means the $p$-value of the significance. 


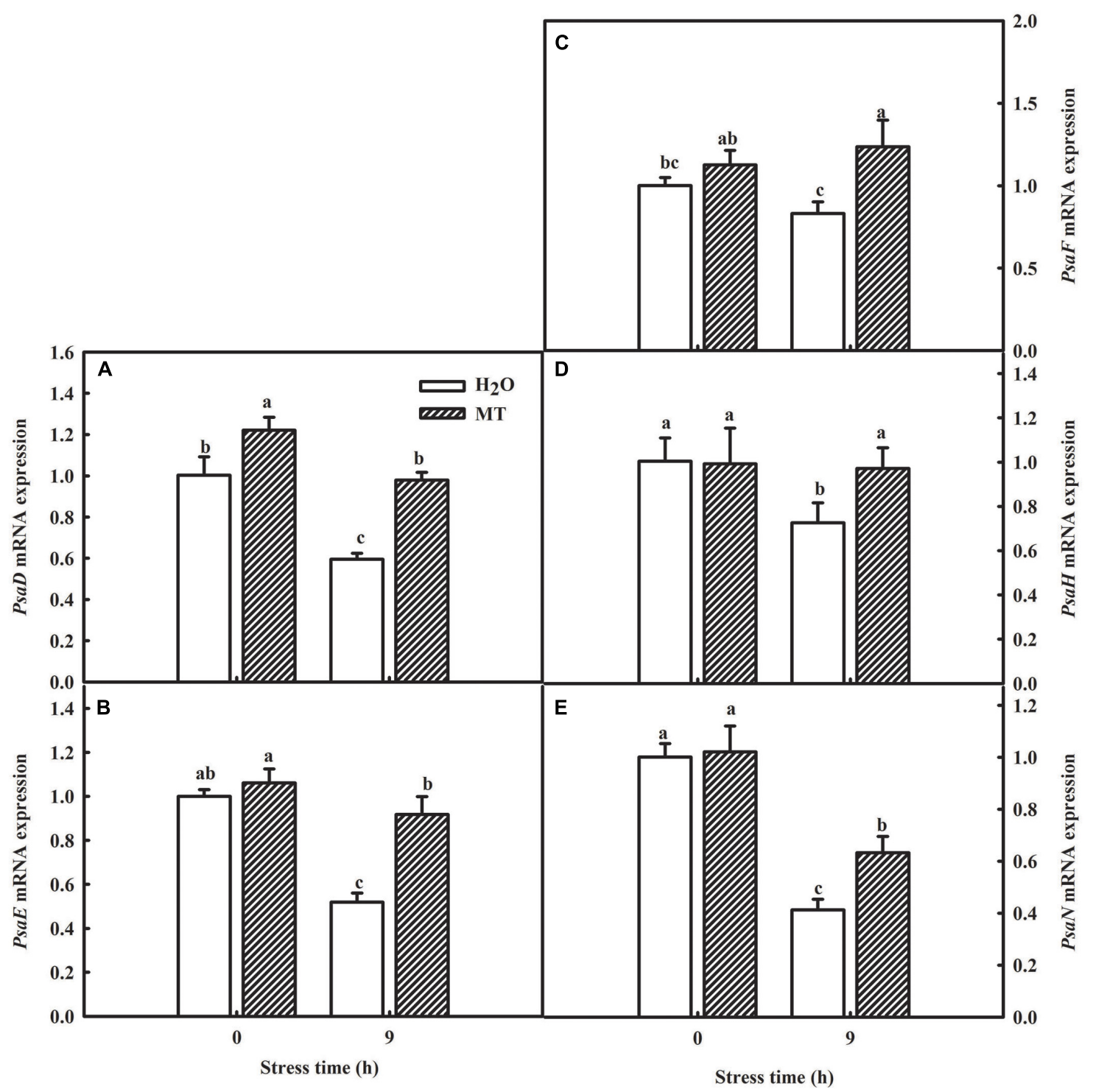

FIGURE 7 | Verification of proteomic results by qRT-PCR. (A) mRNA expression of PsaD; (B) mRNA expression of PsaE; (C) mRNA expression of PsaF; (D) mRNA expression of $P s a H$; (E) mRNA expression of $P$ saN. The two-leaf stage cucumber seedlings were treated with $\mathrm{H}_{2} \mathrm{O}$ and $1.0 \mu \mathrm{mol} \cdot \mathrm{L}^{-1} \mathrm{MT}$, respectively, for $24 \mathrm{~h}$, and then seedlings were exposed to $5^{\circ} \mathrm{C}$ for $9 \mathrm{~h}$. All values shown are mean $\pm \mathrm{SD}(n=3)$. a, b, and c indicate that mean values are significantly different among samples $(p<0.05)$.

TABLE 2 | Functional classifications of identified proteins significantly expressed in cucumber seedlings of MT versus $\mathrm{H}_{2} \mathrm{O}$ plants $(p<0.05$ and a fold change of $>1.2$ or $<1.2$.

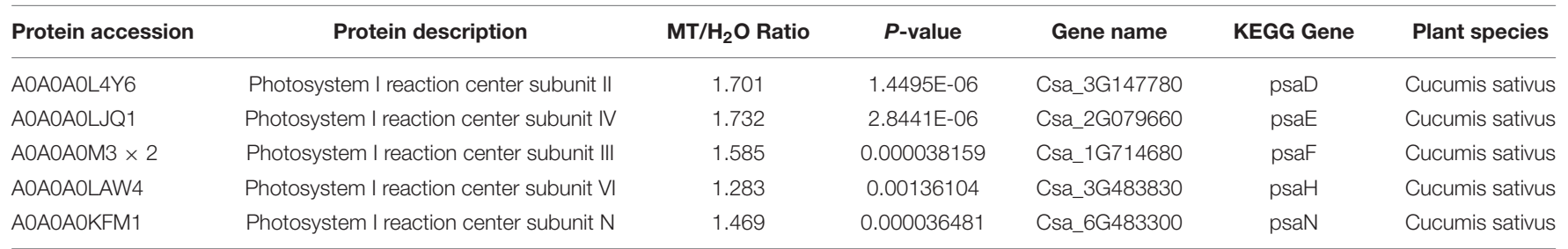

found that the low-temperature intensity led to a decrease in Fv/Fm and ФPSII (Figure 5A); however, the application of MT in cucumber seedlings maintained the higher PSII activity than that in $\mathrm{H}_{2} \mathrm{O}$-treated seedlings at the end of the stress (Figure 5A). The study of the reaction center of PSII and its donor and acceptor sides are considered as important for PSII activity of 


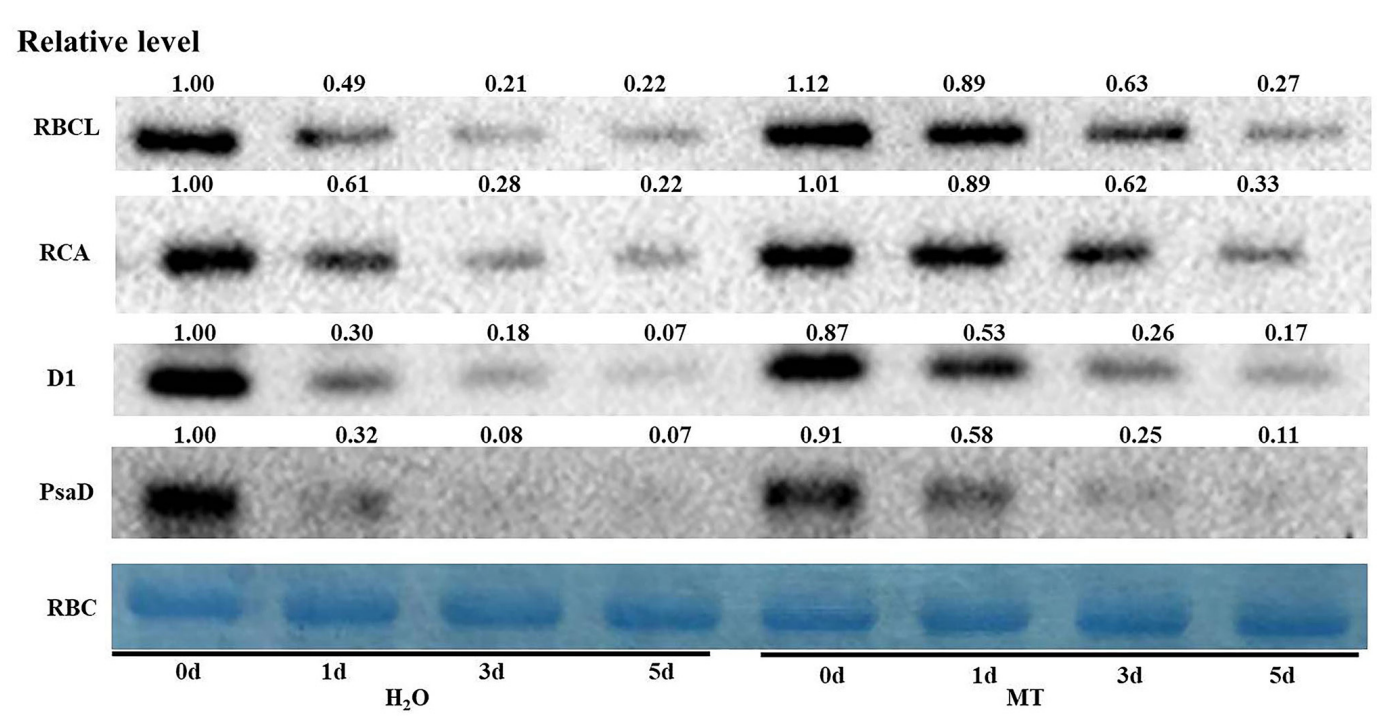

FIGURE 8 | Effect of MT on the protein expression of RBCL, RCA, D1, and PsaD of cucumber seedlings under chilling stress. The two-leaf stage cucumber seedlings were treated with $\mathrm{H}_{2} \mathrm{O}$ and $1.0 \mu \mathrm{mol} \cdot \mathrm{L}^{-1} \mathrm{MT}$, respectively, for $24 \mathrm{~h}$, and then seedlings were exposed to 8 or $5^{\circ} \mathrm{C}$ for 5 days. The leaves for photosynthesis analysis were sampled for total protein extraction. The Rubisco (RBC) was used as an internal reference protein to adjust the concentration of different samples, and the value of $\mathrm{H}_{2} \mathrm{O}$ treatment at $\mathrm{O}$ days was set to 1.

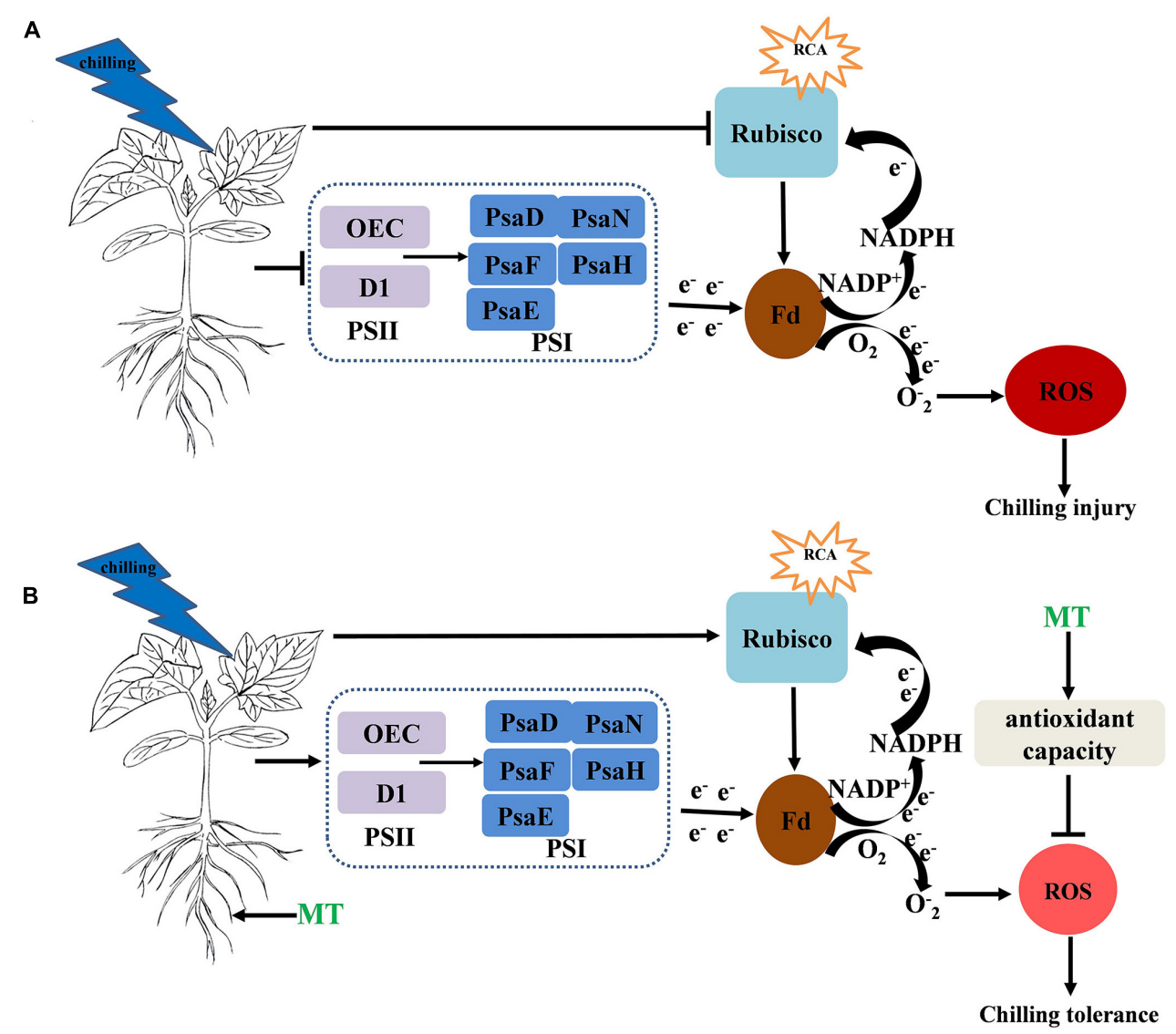

FIGURE 9 | (A,B) Simplified schematic model for MT on the regulation of the chilling tolerance in cucumber $\rightarrow$ indicates upregulation or positive effects. $\perp$ Indicates downregulation or negative effects. The circle and color of ROS indicate the change of ROS content under chilling stress and the darker the color and larger the circle, the higher the content of ROS. 
plants, especially under abiotic stress (Krause and Weis, 1991; Maxwell and Johnson, 2000; Li et al., 2005). In this paper, we observed that MT obviously alleviated the decline of $\mathrm{Rc} / \mathrm{Cs} \mathrm{s}_{\mathrm{m}}$, $\Psi_{0}, \varphi \mathrm{E}_{0}$ and increase of $\triangle \mathrm{V}_{O-J}$ (Figures 5C-G), implying $\mathrm{MT}$ increased the amount of the reaction center, decreased chilling injury to the OEC, and finally protected the electron transfer during chilling stress. PSI in chilling-sensitive plants was thought to be more sensitive than PSII under chilling stress (Terashima et al., 1994; Zhang et al., 2011), and the decrease in PSI was mainly due to the decline in enzyme activity in the dark reaction during the photosynthetic process, further resulting in an increase in the excess excitation energy of PSII under chilling stress (Zhang et al., 2009). In this study, we found that PSI activity was decreased in both MT- and $\mathrm{H}_{2} \mathrm{O}$-treated seedlings (Figure 5B); however, PSI activity in $\mathrm{H}_{2} \mathrm{O}$-treated seedlings decreased the most following 5 days of chilling stress, which may be related to the upregulation of RCA and ribulose-1,5bisphosphate carboxylase or oxygenase (Rubisco) larger subunit protein level by MT (Figure 8). To further provide evidence for the mechanisms by which MT affected photosynthesis to improve the chilling tolerance of cucumber seedlings, we detected the change in proteomic level in cucumber seedlings pretreated with $\mathrm{H}_{2} \mathrm{O}$ and MT under chilling stress. The data showed that MT significantly upregulated 148 proteins that were mainly enriched in photosynthesis pathways following $9 \mathrm{~h}$ of chilling stress (Figure 6). Surprisingly, we found that the change of proteins in photosynthesis was mainly related to PSI, such as PsaD, PsaE, PsaF, PsaH, and PsaN (Table 2); however, none PSII-related proteins were found following $9 \mathrm{~h}$ of chilling stress. In addition, we found that similar to the change of PSII and PSI activity, the western blot results showed MT alleviated the decline in PsaD and D1 protein following 1 day of chilling stress (Figure 8). Our results demonstrated that MT could upregulate the PSI-related protein level earlier than PSII-related protein during the chilling stress to response to PSI photoinhibition occurred earlier than PSII photoinhibition in chilling-sensitive plants (Terashima et al., 1994).

Reactive oxygen species of plants is homeostasis under normal conditions and excess ROS content induced by abiotic stress resulted in the oxidative damage to plants ( $\mathrm{Xu}$ et al., 2019). The reports of Mittler et al. (2011) indicated that ROS in plants occurred mainly through 10 pathways, which included photosynthesis, $\mathrm{RBOH}$ oxidase, photorespiration, etc. It is generally recognized that photoinhibition induced by abiotic stress is the main reason for ROS accumulation in chloroplast, which further affects the photosynthetic apparatus (Savitch et al., 1997). The decrease of electron transfer at the reduction side of PSI during photosynthetic process is the main reason for ROS accumulation in chloroplast under chilling stress (Sonoike, 1996; Zhang et al., 2014). Here, the lower ROS content in MT-treated seedlings was well associated with an increase in $\Delta \mathrm{I} / \mathrm{I}_{0}$ in $\mathrm{MT}$-treated seedlings under chilling stress (Figure 5B). Furthermore, it is obvious that plants showed enhanced chilling tolerance are related to the elevating ROS scavenging capability (Luo et al., 2015; Pan et al., 2020; Zhang et al., 2020). In this study, we found that MT markedly enhanced the activities and relative mRNA expression of antioxidant enzymes, including SOD, POD, CAT, APX, and GR in cucumber seedlings (Figure 3), implying MT participated in the modulation of ROS accumulation through upregulating the mRNA abundance of antioxidant defense genes and further promoted the chilling tolerance, which was consistent with the results of previous studies (Hu et al., 2016; Marta et al., 2016).

\section{CONCLUSION}

In summary, MT induced chilling tolerance in cucumber seedlings, as shown by the decrease in stress-induced electrolyte leakage, the decreased contents of $\mathrm{H}_{2} \mathrm{O}_{2}, \mathrm{MDA}$ and the production rate of $\mathrm{O}_{2}{ }^{-}$, which occurred partially due to the induction of antioxidant metabolism. Additionally, the MT treatment maintained a high photosynthetic carbon assimilation capacity, increased the PSII- and PSI-related protein levels, which increased the activity of the PSII and PSI reaction centers and electron transfer efficiency, thus finally alleviated the damage to photosynthetic apparatus under chilling stress (Figure 9).

\section{DATA AVAILABILITY STATEMENT}

The mass spectrometry proteomics data have been deposited to the ProteomeXchange Consortium via the PRIDE (Website: http://www.ebi.ac.uk/pride) partner repository with the dataset identifier PXD029134.

\section{ETHICS STATEMENT}

The authors declare that the experiments were performed in compliance with the current laws of China.

\section{AUTHOR CONTRIBUTIONS}

$\mathrm{XZ}$ performed most of the experiments, analyzed the data, and completed the first draft. HB designed the research and edited the study. YF, TJ, XL, and XA worked together with XZ to accomplish the experiment. All authors contributed to the article and approved the submitted version.

\section{FUNDING}

This work was supported by the National Key Research and Development Program of China (2019YFD1000300 and 2018YFD1000800), the Major Science and Technology Innovation of Shandong Province in China (2019JZZY010715), and the Special Fund of Modern Agriculture Industrial Technology System of Shandong Province in China (SDAIT-05-10). 


\section{REFERENCES}

Aghdam, M. S., Luo, Z., Li, L., Jannatizadeh, A., Fard, J. R., and Pirzad, F. (2020). Melatonin treatment maintains nutraceutical properties of pomegranate fruits during cold storage. Food Chem. 303:125385. doi: 10.1016/j.foodchem.2019. 125385

Anjum, N. A., Sofo, A., Scopa, A., Roychoudhury, A., Gill, S. S., Iqbal, M., et al. (2015). Lipids and proteins-major targets of oxidative modifications in abiotic stressed plants. Environ. Sci. Pollut. Res. 22, 4099-4121. doi: 10.1007/s11356014-3917-1

Arora, D., and Bhatla, S. C. (2017). Melatonin and nitric oxide regulate sunflower seedling growth under salt stress accompanying differential expression of $\mathrm{Cu} / \mathrm{Zn}$ SOD and Mn SOD. Free Radic. Biol. Med. 106, 315-328. doi: 10.1016/ j.freeradbiomed.2017.02.042

Asada, K. (2006). Production and scavenging of reactive oxygen species in chloroplasts and their functions. Plant Physiol. 141, 391-396. doi: 10.1104/pp. 106.082040

Bajwa, V. S., Shukla, M. R., Sherif, S. M., Murch, S. J., and Saxena, P. K. (2014). Role of melatonin in alleviating cold stress in Arabidopsis thaliana. J. Pineal Res. 56, 238-245. doi: 10.1111/jpi.12115

Barrero-Gil, J., Huertas, R., Rambla, J. L., Granell, A., and Salinas, J. (2016). Tomato plants increase their tolerance to low temperature in a chilling acclimation process entailing comprehensive transcriptional and metabolic adjustments. Plant Cell Environ. 39, 2303-2318. doi: 10.1111/pce.12799

Beyer, W. F., and Fridovich, I. (1987). Assaying for superoxide dismutase activity: some large consequences of minor changes in conditions. Anal. Biochem. 161, 559-566. doi: 10.1016/0003-2697(87)90489-1

Bi, H. G., Dong, X. B., Liu, P. P., Li, Q. M., and Ai, X. Z. (2016). Influence of over expression of CsRCA on photosynthesis of cucumber seedlings under high temperature stress. Chin. J. Appl. Ecol. 27, 2308-2314. doi: 10.13287/j.10019332.201607.028

Bi, H. G., Dong, X. B., Wu, G. X., Wang, M. L., and Ai, X. Z. (2015). Decreased TK activity alters growth, yield and tolerance to low temperature and low light intensity in transgenic cucumber plants. Plant Cell Rep. 34, 345-354. doi: 10.1007/s00299-014-1713-5

Bi, H. G., Liu, P. P., Jiang, Z. S., and Ai, X. Z. (2017). Overexpression of the rubisco activase gene improves growth and low temperature and weak light tolerance in Cucumis sativus. Physiol. Plant. 161, 224-234. doi: 10.1111/ppl.12587

Cabrera, R. M., and Saltveit, M. E. (1990). Physiological response to chilling temperatures of intermittently warmed cucumber fruit. J. Am. Soc. Hortic. Sci. 115, 256-261. doi: 10.21273/JASHS.115.2.256

Cai, B. B., Li, Q., Liu, F. J., Bi, H. G., and Ai, X. Z. (2018). Decreasing fructose-1,6bisphosphate aldolase activity reduces plant growth and tolerance to chilling stress in tomato seedlings. Physiol. Plant. 163, 247-258. doi: 10.1111/ppl.12682

Carrillo-Vico, A., Lardone, P., Álvarez-Sánchez, N., Rodríguez-Rodríguez, A., and Guerrero, J. (2013). Melatonin: buffering the immune system. Int. J. Mol. Sci. 14, 8638-8683. doi: 10.3390/ijms 14048638

Chen, Z., Gu, Q., Yu, X., Huang, L., Xu, S., Wang, R., et al. (2018). Hydrogen peroxide acts downstream of melatonin to induce lateral root formation. Ann. Bot. 121, 1127-1136. doi: 10.1093/aob/mcx207

Cho, U. H., and Park, J. O. (2000). Mercury-induced oxidative stress in tomato seedlings. Plant Sci. 156, 1-9. doi: 10.1016/S0168-9452(00)00227-2

Debnath, B., Islam, W., Li, M., Sun, Y., Lu, X., Mitra, S., et al. (2019). melatonin mediates enhancement of stress tolerance in Plants. Int. J. Mol. Sci. 20:1040. doi: 10.3390/ijms20051040

Ding, F., Wang, M. L., Zhang, S. X., and Ai, X. Z. (2016). Changes in SBPase activity influence photosynthetic capacity, growth, and tolerance to chilling stress in transgenic tomato plants. Sci. Rep. 6:32741. doi: 10.1038/srep32741

Dong, X. B., Bi, H. G., Wu, G. X., and Ai, X. Z. (2013). Drought-induced chilling tolerance in cucumber involves membrane stabilisation improved by antioxidant system. Int. J. Plant Prod. 7, 67-80.

Dubbels, R., Reiter, R. J., Klenke, E., Goebel, A., Schnakenberg, E., Ehlers, C., et al. (1995). Melatonin in edible plants identified by radioimmunoassay and by high performance liquid chromatography-mass spectrometry. J. Pineal Res. 18, 28-31. doi: 10.1111/j.1600-079X.1995.tb00136.x

Erdal, S. (2019). Melatonin promotes plant growth by maintaining integration and coordination between carbon and nitrogen metabolisms. Plant Cell Rep. 38, 1001-1012. doi: 10.1007/s00299-019-02423-z
Eremina, M., Rozhon, W., and Poppenberger, B. (2016). Hormonal control of cold stress responses in plants. Cell. Mol. Life Sci. 73, 797-810. doi: 10.1007/s00018015-2089-6

Fan, J. B., Hu, Z. R., Xie, Y., Chan, Z. L., Chen, K., Amombo, E., et al. (2015). Alleviation of cold damage to photosystem II and metabolisms by melatonin in Bermudagrass. Front. Plant Sci. 6:925. doi: 10.3389/fpls.2015.0 0925

Feng, Y., Fu, X., Han, L., Xu, C., Liu, C., Bi, H., et al. (2021). Nitric oxide functions as a downstream signal for melatonin-induced cold tolerance in cucumber seedlings. Front. Plant Sci. 12:686545. doi: 10.3389/fpls.2021.686545

Foyer, C., and Halliwell, B. (1976). The presence of glutathione and glutathione reductase in chloroplasts: a proposed role in ascorbic acid metabolism. Planta 133, 21-25. doi: 10.1007/BF00386001

Galluzzi, L., and Kroemer, G. (2014). "Conceptual background and bioenergetic/mitochondrial aspects of oncometabolism," in Methods in Enzymology, Vol. 542, ed. G. Kroemer (San Diego, CA: Academic Press).

Gao, J. L., Wang, H., Yuan, Q. P., and Feng, Y. (2018). Structure and function of the photosystem supercomplexes. Front. Plant Sci. 9:357. doi: 10.3389/fpls.2018. 00357

Gong, J., and Xiang, J. (2001). Studies on a quick intact measurement to cucumber colony's leaf area. China Vegetables 4, 7-9.

Hardeland, R., Madrid, J. A., Tan, D. X., and Reiter, R. J. (2012). Melatonin, the circadian multioscillator system and health: the need for detailed analyses of peripheral melatonin signaling. J. Pineal Res. 52, 139-166. doi: 10.1111/j.1600079X.2011.00934.x

Hasanuzzaman, M., Hossain, M. A., Silva, J. A. T. D., and Fujita, M. (2012). "Plant response and tolerance to abiotic oxidative stress: antioxidant defense is a key factor," in Crop Stress and its Management: Perspectives and Strategies, eds B. Venkateswarlu, A. K. Shanker, C. Shanker, and M. Maheswari (Dordrecht: Springer Press), 261-315.

Hattori, A., Migitaka, H., Iigo, M., Itoh, M., Yamamoto, K., Ohtani-Kaneko, R., et al. (1995). Identification of melatonin in plants and its effects on plasma melatonin levels and binding to melatonin receptors in vertebrates. Biochem. Mol. Biol. Int. 35, 627-634.

Heath, R. L., and Packer, L. (1968). Photoperoxidation in isolated chloroplasts: I. Kinetics and stoichiometry of fatty acid peroxidation. Arch. Biochem. Biophys. 125, 189-198. doi: 10.1016/0003-9861(68)90654-1

Hu, Z., Fan, J., Xie, Y., Amombo, E., Liu, A., Gitau, M. M., et al. (2016). Comparative photosynthetic and metabolic analyses reveal mechanism of improved cold stress tolerance in bermudagrass by exogenous melatonin. Plant Physiol. Biochem. 100, 94-104.

Iqbal, N., Fatma, M., Gautam, H., Umar, S., Sofo, A., D’ippolito, I., et al. (2021). The crosstalk of melatonin and hydrogen sulfide determines photosynthetic performance by regulation of carbohydrate metabolism in wheat under heat stress. Plants 10:1778. doi: 10.3390/plants10091778

Jajic, I., Sarna, T., and Strzalka, K. (2015). Senescence, stress, and reactive oxygen species. Plants 4, 393-411. doi: 10.3390/plants4030393

Jan, J. E., Reiter, R. J., Wasdell, M. B., and Bax, M. (2009). The role of the thalamus in sleep, pineal melatonin production, and circadian rhythm sleep disorders. J. Pineal Res. 46, 1-7. doi: 10.1111/j.1600-079X.2008.00628.x

Kazemi-Shahandashti, S. S., and Maali-Amiri, R. (2018). Global insights of protein responses to cold stress in plants: signaling, defence, and degradation. J. Plant Physiol. 226, 123-135. doi: 10.1016/j.jplph.2018.03.022

Kong, F. Y., Deng, Y. S., Zhou, B., Wang, G. D., Wang, Y., and Meng, Q. W (2014). A chloroplast-targeted DnaJ protein contributes to maintenance of photosystem II under chilling stress. J. Exp. Bot. 65, 143-158. doi: 10.1093/jxb/ ert357

Krause, G. H., and Weis, E. (1991). Chlorophyll fluorescence and photosynthesis: the basics. Annu. Rev. Plant Physiol. Plant Mol. Biol. 42, 319-349. doi: 10.1146/ annurev.pp.42.060191.001525

Lee, S. H., Singh, A. P., Chung, G. C., Kim, Y. S., and Kong, I. B. (2002) Chilling root temperature causes rapid ultrastructural changes in cortical cells of cucumber (Cucumis sativus L.) root tips. J. Exp. Bot. 53, 2225-2237. doi: $10.1093 / \mathrm{jxb} / \mathrm{erf071}$

Lei, X. Y., Zhu, R. Y., Zhang, G. Y., and Dai, Y. R. (2004). Attenuation of coldinduced apoptosis by exogenous melatonin in carrot suspension cells: the possible involvement of polyamines. J. Pineal Res. 36, 126-131. doi: 10.1046/ j.1600-079X.2003.00106.x 
Lerner, A. B., Case, J. D., Takahashi, Y., Lee, T. H., and Mori, W. (1958). Isolation of melatonin, the pineal gland factor that lightens melanocytes. J. Am. Chem. Soc. 80:2587. doi: 10.1021/ja01543a060

Li, H., Chang, J. J., Chen, H. J., Wang, Z. Y., Gu, X. R., Wei, C. H., et al. (2017). Exogenous melatonin confers salt stress tolerance to watermelon by improving photosynthesis and redox homeostasis. Front. Plant Sci. 8:295. doi: 10.3389/fpls. 2017.00295

Li, M. Q., Hasan, M. K., Li, C. X., Ahammed, G. J., Xia, X. J., Shi, K., et al. (2016). Melatonin mediates selenium-induced tolerance to cadmium stress in tomato plants. J. Pineal Res. 61, 291-302. doi: 10.1111/jpi.12346

Li, P. M., Gao, H. Y., and Strasser, R. J. (2005). Application of the chlorophyll fluorescence induction dynamics in photosynthesis study. J. Plant Physiol. Mol. Biol. 31, 559-566. doi: 10.1360/aps040074

Li, X. N., Brestic, M., Tan, D. X., Zivcak, M., Zhu, X., Liu, S. Q., et al. (2017). Melatonin alleviates low PS I-limited carbon assimilation under elevated $\mathrm{CO} 2$ and enhances the cold tolerance of offspring in chlorophyll b-deficient mutant wheat. J. Pineal Res. 64:e12453. doi: 10.1111/jpi.12453

Liang, D., Ni, Z. Y., Xia, H., Xie, Y., Lv, X. L., Wang, J., et al. (2019). Exogenous melatonin promotes biomass accumulation and photosynthesis of kiwifruit seedlings under drought stress. Sci. Hortic. 246, 34-43. doi: 10.1016/j.scienta. 2018.10.058

Liu, F. J., Fu, X., Wu, G. X., Feng, Y. Q., Li, F. D., Bi, H. G., et al. (2020). Hydrogen peroxide is involved in hydrogen sulfide-induced carbon assimilation and photoprotection in cucumber seedlings. Environ. Exp. Bot. 175:104052. doi: 10.1016/j.envexpbot.2020.104052

Luo, Z., Li, D., Du, R., Mou, W., and Mao, L. (2015). Hydrogen sulfide alleviates chilling injury of banana fruit by enhanced antioxidant capacity and proline content. Sci. Hortic. 183, 144-151. doi: 10.1016/j.scienta.2014.12.021

Ma, X., Chen, C., Yang, M., Dong, X., Lv, W., and Meng, Q. (2018). Cold-regulated protein (SICOR413IM1) confers chilling stress tolerance in tomato plants. Plant Physiol. Biochem. 124, 29-39. doi: 10.1016/j.plaphy.2018.01.003

Maehly, A. C., and Chance, P. (1955). Assay of catalase and peroxidases. Methods Enzymol. 2, 764-775.

Maronde, E., and Stehle, J. H. (2007). The mammalian pineal gland: known facts, unknown facets. Trends Endocrinol. Metab. 18, 142-149. doi: 10.1016/j.tem. 2007.03.001

Marta, B., Szafrańska, K., and Posmyk, M. M. (2016). Exogenous melatonin improves antioxidant defense in cucumber seeds (Cucumis sativus L.) germinated under chilling stress. Front. Plant Sci. 7:575. doi: 10.3389/fpls.2016. 00575

Maxwell, K., and Johnson, G. N. (2000). Chlorophyll fluorescence-a practical guide. J. Exp. Bot. 51, 659-668. doi: 10.1093/jexbot/51.345.659

Mittler, R., Vanderauwera, S., Suzuki, N., Miller, G., Tognetti, V. B., Vandepoele, K., et al. (2011). ROS signaling: the new wave? Trends Plant Sci. 16, 300-309. doi: 10.1016/j.tplants.2011.03.007

Nakano, Y., and Asada, K. (1987). Purification of ascorbate peroxidase in spinach chloroplasts; its inactivation in ascorbate-depleted medium and reactivation by monodehydroascorbate radical. Plant Cell Physiol. 28, 131-140. doi: 10.1093/ oxfordjournals.pcp.a077268

Omran, R. G. (1980). Peroxide levels and the activities of catalase, peroxidase, and indoleacetic acid oxidase during and after chilling cucumber seedlings. Plant Physiol. 65, 407-408. doi: 10.1104/pp.65.2.407

Pan, D. Y., Fu, X., Zhang, X. W., Liu, F. J., Bi, H. G., and Ai, X. Z. (2020). Hydrogen sulfide is required for salicylic acid-induced chilling tolerance of cucumber seedlings. Protoplasma 257, 1543-1557. doi: 10.1007/s00709-020-01531-y

Pandi-Perumal, S. R., Trakht, I., Srinivasan, V., Spence, D. W., Maestroni, G. J., Zisapel, N., et al. (2008). Physiological effects of melatonin: role of melatonin receptors and signal transduction pathways. Prog. Neurobiol. 85, 335-353. doi: 10.1016/j.pneurobio.2008.04.001

Posmyk, M. M., Baabusta, M., Wieczorek, M., Sliwinska, E., and Janas, K. M. (2009). Melatonin applied to cucumber (Cucumis sativus L.) seeds improves germination during chilling stress. J. Pineal Res. 46, 214-223. doi: 10.1111/j. 1600-079X.2008.00652.x

Rai, A. C., Singh, M., and Shah, K. (2012). Effect of water withdrawal on formation of free radical, proline accumulation and activities of antioxidant enzymes in ZAT12-transformed transgenic tomato plants. Plant Physiol. Biochem. 61, 108-114. doi: 10.1016/j.plaphy.2012.09.010
Ren, J., Yang, X., Ma, C., Wang, Y., and Zhao, J. (2021). Melatonin enhances drought stress tolerance in maize through coordinated regulation of carbon and nitrogen assimilation. Plant Physiol. Biochem. 167, 958-969. doi: 10.1016/j. plaphy.2021.09.007

Salvatori, E., Fusaro, L., Gottardini, E., Pollastrini, M., Goltsev, V., Strasser, R. J., et al. (2014). Plant stress analysis: application of prompt, delayed chlorophyll fluorescence and $820 \mathrm{~nm}$ modulated reflectance. Insights from independent experiments. Plant Physiol. Biochem. 85, 105-113. doi: 10.1016/j.plaphy.2014. 11.002

Savitch, L. V., Gray, G. R., and Huner, N. P. A. (1997). Feedback-limited photosynthesis and regulation of sucrose-starch accumulation during cold acclimation and low temperature stress in a spring and winter wheat. Planta 201, 18-26. doi: 10.1007/BF01258676

Semeniuk, P., Moline, H. E., and Abbott, J. A. (1986). A comparison of the effects of ABA and an antitranspirant on chilling injury of coleus, cucumbers, and dieffenbachia. J. Am. Soc. Hortic. Sci. 111, 241-257. doi: 10.1002/ 9781118609576.ch7

Shi, H., Jiang, C., Ye, T., Tan, D. X., Reiter, R. J., Zhang, H., et al. (2015). Comparative physiological, metabolomic, and transcriptomic analyses reveal mechanisms of improved abiotic stress resistance in bermudagrass [Cynodon dactylon (L). Pers.] by exogenous melatonin. J. Exp. Bot. 66, 681-694. doi: $10.1093 / \mathrm{jxb} / \mathrm{eru} 373$

Sonoike, K. (1996). Photoinhibition of photosystem I: its physiological significance in the chilling sensitivity of plants. Plant Cell Physiol. 37, 239-247. doi: 10.1093/ oxfordjournals.pcp.a028938

Strasser, R. J., Tsimilli-Michael, M., Qiang, S., and Goltsev, V. (2010). Simultaneous in vivo recording of prompt and delayed fluorescence and 820-nm reflection changes during drying and after rehydration of the resurrection plant Haberlea rhodopensis. Biochim. Biophys. Acta 1797, 1313-1326. doi: 10.1016/j.bbabio. 2010.03.008

Terashima, I., Funayama, S., and Sonoike, K. (1994). The site of photoinhibition in leaves of Cucumis sativus L. at low temperatures is photosystem I, not photosystem II. Planta 193, 300-306. doi: 10.1007/BF00192544

Terashima, I., Noguchi, K., Itoh-Nemoto, T., Park, Y. M., and Tanaka, K. (1998). The cause of psi photoinhibition at low temperatures in leaves of cucumis sativus, a chilling-sensitive plant. Physiol. Plant. 103, 295-303. doi: 10.1034/j. 1399-3054.1998.1030301.x

Tian, Y. L., Ungerer, P., Zhang, H. Y., and Ruban, A. V. (2017). Direct impact of the sustained decline in the photosystem II efficiency upon plant productivity at different developmental stages. J. Plant Physiol. 212, 45-53. doi: 10.1016/j.jplph. 2016.10.017

Tikkanen, M., Rantala, S., and Aro, E. M. (2015). Electron flow from PSII to PSI under high light is controlled by PGR5 but not by PSBS. Front. Plant Sci. 6:521. doi: 10.3389/fpls.2015.00521

Wang, A. G., and Luo, G. H. (1990). Quantitative relation between the reaction of hydroxylamine and superoxide anion radicals in plants. Plant Physiol. Commun. 26, 55-57. doi: 10.1021/ja00874a010

Xu, Y., Charles, M. T., Luo, Z., Mimee, B., Chao, T., Veronneau, P. Y., et al. (2019). Ultraviolet-C priming of strawberry leaves against subsequent Mycosphaerella fragariae infection involves the action of reactive oxygen species, plant hormones, and terpenes. Plant Cell Environ. 42, 815-831. doi: 10.1111/pce. 13491

Yan, F. Y., Zhang, J. Y., Li, W. W., Ding, Y. F., Zhong, Q. Y., Xu, X., et al. (2021). Exogenous melatonin alleviates salt stress by improving leaf photosynthesis in rice seedlings. Plant Physiol. Biochem. 163, 367-375. doi: 10.1016/j.plaphy.2021. 03.058

Yu, J. Q., Zhou, Y. H., Huang, L. F., and Allen, D. J. (2002). Chill-induced inhibition of photosynthesis: genotypic variation within Cucumis sativus. Plant Cell Physiol. 43, 1182-1188. doi: 10.1093/pcp/pcf134

Zhang, X. W., Liu, F. J., Zhai, J., Li, F. D., Bi, H. G., and Ai, X. Z. (2020). Auxin acts as a downstream signaling molecule involved in hydrogen sulfide-induced chilling tolerance in cucumber. Planta 251:69. doi: 10.1007/s00425-02003362-w

Zhang, Z. S., Jia, Y. J., Gao, H. Y., Zhang, L. T., Li, H. D., and Meng, Q. W. (2011). Characterization of PSI recovery after chilling-induced photoinhibition in cucumber (Cucumis sativus L.) Leaves. Planta 234, 883-889. doi: 10.1007/ s00425-011-1447-3 
Zhang, Z. S., Jin, L. Q., Li, Y. T., Tikkanen, M., Li, Q. M., Ai, X. Z., et al. (2016). Ultraviolet-b radiation (UV-B) relieves chilling-light-induced PSI photoinhibition and accelerates the recovery of $\mathrm{CO} 2$ assimilation in cucumber (Cucumis sativus L.) leaves. Sci. Rep. 6:34455. doi: 10.1038/srep 34455

Zhang, Z. S., Yang, C., Gao, H. Y., Zhang, L. T., Fan, X. L., and Liu, M. J. (2014). The higher sensitivity of PSI to ROS results in lower chilling-light tolerance of photosystems in young leaves of cucumber. J. Photochem. Photobiol. B 137, 127-134. doi: 10.1016/j.jphotobiol.2013.12.012

Zhang, Z. S., Zhang, L. T., Gao, H. Y., Jia, Y. J., Bu, J. W., and Meng, Q. W. (2009). Research of the photoinhibition of PS and PSII in leaves of cucumber under chilling stress combined with different light intensities. Sci. Agric. Sin. 42, 4288-4293.

Zhao, H., Ye, L., Wang, Y., Zhou, X., Yang, J., Wang, J., et al. (2016). Melatonin increases the chilling tolerance of chloroplast in cucumber seedlings by regulating photosynthetic electron flux and the ascorbate-glutathione cycle. Front. Plant Sci. 7:1814. doi: 10.3389/fpls.2016.01814

Zhuang, K. Y., Kong, F. Y., Zhang, S., Meng, C., Yang, M. M., Liu, Z. B., et al. (2019). Whirlyl enhances tolerance to chilling stress in tomato via protection of photosystem II and regulation of starch degradation. New Phytol. 221, 1998-2012. doi: 10.1111/nph.15532
Zuo, B., Zheng, X., He, P., Wang, L., Lei, Q., Feng, C., et al. (2014). Overexpression of MzASMT improves melatonin production and enhances drought tolerance in transgenic Arabidopsis thaliana plants. J. Pineal Res. 57, 408-417. doi: 10. 1111/jpi.12180

Conflict of Interest: The authors declare that the research was conducted in the absence of any commercial or financial relationships that could be construed as a potential conflict of interest.

Publisher's Note: All claims expressed in this article are solely those of the authors and do not necessarily represent those of their affiliated organizations, or those of the publisher, the editors and the reviewers. Any product that may be evaluated in this article, or claim that may be made by its manufacturer, is not guaranteed or endorsed by the publisher.

Copyright (c) 2021 Zhang, Feng, Jing, Liu, Ai and Bi. This is an open-access article distributed under the terms of the Creative Commons Attribution License (CC BY). The use, distribution or reproduction in other forums is permitted, provided the original author(s) and the copyright owner(s) are credited and that the original publication in this journal is cited, in accordance with accepted academic practice. No use, distribution or reproduction is permitted which does not comply with these terms. 